\title{
A Component GARCH Model with Time Varying Weights
}

L. Bauwens and G. Storti

Discussion Paper 2007-12

Département des Sciences Économiques

de l'Université catholique de Louvain 


\title{
CORE DISCUSSION PAPER
}

$2007 / 19$

\section{A COMPONENT GARCH MODEL WITH TIME VARYING WEIGHTS}

\author{
L. Bauwens ${ }^{1}$ and G. Storti ${ }^{2}$
}

February 16, 2007

\begin{abstract}
We present a novel GARCH model that accounts for time varying, state dependent, persistence in the volatility dynamics. The proposed model generalizes the component GARCH model of Ding and Granger (1996). The volatility is modelled as a convex combination of unobserved GARCH components where the combination weights are time varying as a function of appropriately chosen state variables. In order to make inference on the model parameters, we develop a Gibbs sampling algorithm. Adopting a fully Bayesian approach allows to easily obtain medium and long term predictions of relevant risk measures such as value at risk and expected shortfall. Finally we discuss the results of an application to a series of daily returns on the S\&P500.
\end{abstract}

Keywords: GARCH, persistence, volatility components, value-at-risk, expected shortfall.

JEL Classification: C11, C15, C22

\footnotetext{
${ }^{1}$ CORE and Department of Economics, Université Catholique de Louvain.

${ }^{2}$ STATLAB and Department of Economics and Statistics, Università di Salerno.

Bauwens's work was supported in part by the European Community's Human Potential Programme under contract HPRN-CT-2002-00232, MICFINMA and by a FSR grant from UCL.

This text presents research results of the Belgian Program on Interuniversity Poles of Attraction initiated by the Belgian State, Prime Minister's Office, Science Policy Programming. The scientific responsibility is assumed by the authors.
} 


\section{Introduction}

In the past two decades the empirical evidence from financial markets has shown that the pattern of response of market volatility to shocks is highly dependent on the magnitude of these shocks. In particular, in several papers (among others, Hamilton and Susmel, 1994; Lamoureux and Lastrapes, 1990; 1993), it has been shown that the persistence of the volatility process tends to decrease after extreme events such as those observed in October 1987 and September 2001. Nelson (1992) has provided a theoretical investigation of this phenomenon. Formalizing the empirical intuition, the effects on the conditional variance process of shocks occurring during turbulent periods such as market crashes are much less persistent than the effects of shocks occurring during normal periods. Since GARCH models equally weight all the shocks, this feature is expected to have relevant effects on their ability to producing accurate long term predictions of volatility and related risk measures. Furthermore, it has been documented how structural breaks in the volatility process can give rise to spurious volatility persistence if a GARCH model is fitted to the data without accounting for the breaks (Lamoureux and Lastrapes, 1990; Mikosch and Starica, 2004).

These findings suggest that there are relevant settings in which the dynamic structure of volatility cannot be adequately captured by constant parameter GARCH models. Consequently, we have assisted to a growing interest in adaptive volatility models, characterized by time varying parameters, allowing to account for both structural breaks as well as state dependence of the volatility response. One class of such models is that of smooth transition GARCH models (ST-GARCH) developed by Luukkonen et al. 1988 (see also Lubrano, 2001). These models have smoothly changing parameters. Another class is that of regime-switching GARCH (RS-GARCH) models, first proposed by Hamilton and Susmel (1994) for a purely ARCH specification, and extended by Gray (1994). These models are a valuable tool for including state dependence in the dynamics of the volatility process. However, the diffusion of these models in practical financial modelling is still limited by the severe difficulties arising in their estimation. These mainly originate from the fact that (in the generalized ARCH case) the conditional variance at a given time point $t$ and, hence, the conditional likelihood, cannot be explicitly calculated unless the full set of regimes visited by the process at previous time points is known. A review of recent contributions on the estimation of RS-GARCH models can be found in Bauwens et al. (2006) who also propose a Bayesian approach to the 
estimation of a RS-GARCH model by means of a Gibbs sampling algorithm.

In this paper we propose a modification of the standard GARCH model, which allows time varying persistence in the volatility dynamics. Namely, a lower degree of persistence is assigned to extreme returns taking place in highly volatile periods rather than to shocks of lower magnitude occurring in tranquil periods. However, the model structure could be easily modified to account for more general situations in which variations in the volatility persistence originate from different sources such as, for example, leverage effects and intraday or intraweek seasonal effects in volatility. It is important to note that, on an observational ground, our model is able to reproduce most of the stylized features for which RS-GARCH model have been designed but, at the same time, it is still characterized by tractable inference procedures.

We name the specification proposed in this paper the weighted-GARCH (WGARCH) model. It is a generalization of the component GARCH model of Ding and Granger (1996), henceforth DG, further studied and modified by Engle and Lee (1999), in which the weights associated to the model components are time varying and can depend on adequately chosen state variables, such as lagged values of the conditional standard deviation or squared past returns. Maheu (2005) has recently shown, by means of a simulation study, that a modification of the basic two component DG model is potentially able to reproduce long-memory properties in the autocorrelation of squared returns and, consequently, to account for long range dependence in the volatility dynamics.

Moreover, likelihood based inference for the WGARCH is readily available since the conditional log-likelihood function can be obtained in a straightforward manner by means of a standard prediction error decomposition and maximized using routine optimization algorithms. In the paper we report estimation results for the WGARCH model under the assumption of normal or Student's $t$ errors. ${ }^{1}$ Obtaining Maximum Likelihood (ML) estimates of the model parameters under alternative distributional assumptions, such as the skew- $t$ distribution proposed by Bauwens and Laurent (2005), is a relatively straightforward extension.

Furthermore, despite of the computational simplicity of the ML approach, we show that resorting to Bayesian inference can offer some relevant advantages if the modeller is interested

\footnotetext{
${ }^{1}$ In the first case, in settings in which the conditional normality assumptions is likely to be violated, the estimates can be interpreted as Quasi Maximum Likelihood Estimates (QMLE).
} 
in generating long term forecasts of volatility and associated risk measures such as value at risk (VaR) (for an introductory reading see Jorion, 1997) and expected shortfall (ES) (Artzner et al., 1999).

Accounting for time varying persistence in the volatility dynamics, WGARCH models can potentially lead to more accurate medium and long term VaR and ES forecasts compared to standard GARCH models. If our main interest is only in computing one step ahead predictions, these are easily obtained as a by-product of the maximum likelihood estimation algorithm. Nevertheless, some complications arise when we move to the general case in which we are interested in computing multi-step ahead VaR and ES predictions. In this case, it becomes necessary to compute the conditional expectation of the volatility at time $T+h$ given past and present information available at time $T\left(I^{T}\right)$, which is the optimal predictor of the conditional variance given $I^{T}$ for a quadratic loss function. For standard GARCH models it is possible to derive an analytical expression of this conditional expectation exploiting the associated ARMA representation for squared returns (Baillie and Bollerslev, 1992). Differently, in WGARCH models this representation is non-linear and, consequently, the analytical derivation of a closed form expression for multi-step volatility predictors becomes unfeasible.

At first glance, the use of Monte Carlo simulations from the estimated model appears to be the most natural and immediate solution to this kind of problem. However, a naive Monte Carlo procedure is not able to incorporate any information on parameter uncertainty and the value of the generated predictions is highly dependent on the estimated model parameters. Differently said, parameter uncertainty is naturally dealt with if we resort to a Bayesian approach based on MCMC techniques.

From a conceptual as well as an operational point of view, Bayesian inference offers a natural framework for dealing with the problem of estimating VaR and ES for possibly long holding periods. This is accomplished by a two step procedure. First, we generate a sample from the posterior distribution of the model parameters by means of a Gibbs sampling algorithm nesting a Metropolis step, for the conditional mean parameters, and a griddy Gibbs sampler (Bauwens and Lubrano, 1998), for the conditional variance parameters. Second, we simulate from the predictive distribution of returns conditional on the sample of parameter values drawn at the first step. VaR and ES predictions are then easily computed from the simulated predictive distribution of returns. 
The structure of the paper is as follows. In Section 2 the WGARCH model is proposed and discussed. Problems related to likelihood inference and volatility prediction are discussed in Section 3. In Section 4 we illustrate a Bayesian inference procedure for estimating the model parameters while the algorithm for generating VaR and ES predictions is discussed in Section 5. In Section 6 we present the results of an application of the proposed modeling approach to daily stock returns and in Section 7 we conclude.

\section{The model}

Let $r_{t}$ be a time series of returns on a given asset and denote by $I^{t}$ the set of information available at time $t$, consisting of $X_{t}$ and the returns observed up to time $t, R^{t}=\left(r_{0}, r_{1}, \ldots, r_{t}\right)$. The following equations define a conditionally heteroskedastic model for $r_{t}$ allowing regime switching in the conditional variance of the process:

$$
\begin{aligned}
r_{t} & =\boldsymbol{\beta}^{\prime} X_{t}+u_{t} \\
u_{t} & =z_{t} \sqrt{s_{t-d} h_{1 t}^{2}+\left(1-s_{t-d}\right) h_{2 t}^{2}} \quad t=1, \ldots, T .
\end{aligned}
$$

In the previous equation, $s_{t-d}$ is a Bernoulli random variable, with $d(>0)$ being the delay needed for $s_{t}$ to affect the conditional variance dynamics, $z_{t}$ is an $i i d \sim(0,1)$ sequence of random variables and $h_{k t}^{2}(k=1,2)$ is assumed to be given by the following $\operatorname{GARCH}(\mathrm{p}, \mathrm{q})$ equations:

$$
h_{k t}^{2}=a_{0 k}+\sum_{i=1}^{p} a_{i k} u_{t-i}^{2}+\sum_{j=1}^{q} b_{j k} h_{1, t-j}^{2}
$$

where $\left(a_{i k}, b_{j k}\right)$ are constant coefficients satisfying the constraints $a_{0 k}>0, a_{i k} \geq 0$ and $b_{j k} \geq 0$, for $i=1, \ldots, p, j=1, \ldots, q$ and $k=1,2$. The conditional mean of $r_{t}$ is modeled as a linear function of a $(r \times 1)$ vector of observable explanatory variables $X_{t}$, with $\boldsymbol{\beta}$ being a $(r \times 1)$ vector of unknown coefficients. This specification is general enough to cover the case of a linear autoregressive scheme with exogenous explanatory variables (ARX). Furthermore, it can be easily extended to cover an ARMA dependence structure by simply including past values of $u_{t}$ in $X_{t}$. From equation (2) it follows that the conditional variance of $r_{t}$ given past information $I^{t-1}$ is given by

$$
h_{t}^{2}=w_{t-d} h_{1 t}^{2}+\left(1-w_{t-d}\right) h_{2 t}^{2}
$$


with $w_{t-d}=E\left(s_{t-d} \mid I^{t-1}\right)$. For ease of exposition, the orders of the two GARCH components $h_{k t}^{2}(k=1,2)$ have been assumed to be the same. However it must be observed that, in theory, not only different values of $p$ and $q$ could be used but the two components could be even assumed to follow different models. This for example could be useful in order to reflect the different memory properties of the market in turbulent and tranquil periods. A related model is analyzed by Bauwens et al. (2006) although the specification considered in their paper differs from ours since we allow each volatility component to depend on its own past values $\left(h_{k t}^{2}\right)$ and not on lagged values of $h_{t}^{2}$. The motivation for this choice is twofold. First, it allows a clear cut economic interpretation of the volatility components and their parameters (see the discussion in Haas et al., 2004, p. 498). Second, in this way we prevent the volatility dynamics from being path dependent. The model specification in (2) admits a second order equivalent representation which can be obtained by simply replacing the definition of $u_{t}$ given in (2) by the following

$$
u_{t}=z_{t} \sqrt{w_{t-d} h_{1 t}^{2}+\left(1-w_{t-d}\right) h_{2 t}^{2}}=z_{t} \sqrt{h_{t}^{2}}
$$

The property of second order equivalence means that the model (5) admits the same first two conditional moments as model (2). Nevertheless, working with equation (5) leads to a substantial simplification of the associated inference procedures. The estimation of the parameters in (5), which henceforth will be denoted as a Weighted GARCH model of order(p,q), abbreviated WGARCH(p,q), can be easily performed by standard techniques, Maximum Likelihood (ML) or Gaussian Quasi Maximum Likelihood (QML). Furthermore, we explain in Section 4 that working with (5) implies relevant practical advantages if one is interested in generating long term forecasts of VaR and ES within a fully Bayesian setting. Equation (4) allows to account for the state dependent features of the volatility process by modelling it as a weighted average of two components whose weights change as a function of observable state variables. A suitable choice for the weight function is the logistic function

$$
w_{t-d}=\frac{1}{1+\exp \left(\gamma\left(\delta-v_{t-d}\right)\right)}, \quad \gamma>0
$$

where $(\gamma, \delta)$ are unknown coefficients, and $v_{t}$ is an appropriately chosen state variable. The positivity restriction on $\gamma$ is explained below.

As state variable we can consider the conditional standard deviation $h_{t-d}$ to reflect the tendency of volatility to be less persistent in turbulent periods than in tranquil ones. Alter- 
natively, the absolute value of the past shock $u_{t-d}$ could be used. In this respect, it is worth stressing that using the past shock $\left(u_{t-d}\right)$ as state variable allows the weight $w_{t}$ to depend on information up to time $t-d$ while only information up to time $t-d-1$ can be considered if we choose the conditional standard deviation as a state variable. However we prefer to model the weights as a function of $h_{t-d}$ rather than $\left|u_{t-d}\right|$ since the conditional standard deviation gives a smoother measure of market volatility. The proposed specification can be extended to accommodate a variety of situations in which the volatility dynamics are characterized by one or several state dependent features. For example, by appropriately selecting the state variables in (6), many other situations such as leverage and seasonal effects could be dealt with.

The logistic function has been extensively used in the already mentioned literature on ST-GARCH models and by Bauwens et al. (2006) in the context of RS-GARCH models. The value of $\gamma$ can be interpreted as determining the speed of transition from one component to the other one: the higher $\gamma$ (in modulus), the faster the transition. The positivity constraint $\gamma>0$ is an identification restriction and has the effect of associating the first volatility component $h_{1 t}^{2}$ with the high volatility regime. This is evident since when $h_{t-d}$ tends to $\infty$, $w_{t-d}$ tends to 1 leading to virtually exclude the other component $h_{2 t}^{2}$ whose weight tends to zero. Similarly, the weight of $h_{1 t}^{2}$ reaches its minimum value of $(1+\exp (\gamma \delta))^{-1}$ when $h_{t-d}=0$. Also, for $\gamma$ tending to $0, w_{t-d}$ tends to $(1+\exp (0))^{-1}$ and the WGARCH model tends to a constant weight component GARCH model. This creates a local identification problem involving the constants $\left(a_{0 i}\right)$ and the $\mathrm{ARCH}$ coefficients $\left(a_{j i}\right)$ of the volatility components, $i=1,2, j=1, \ldots, p$.

Strictly speaking the model is always identified unless $\gamma$ is exactly equal to zero. However, even when the value of $\gamma$ is positive but very close to zero, the resulting likelihood surface can be quite flat giving rise to numerical instabilities in the estimation of parameters. If we focus on the case of a model of order $(1,1)$, as is the case in most financial applications, this local identifiability problem can be easily solved by forcing $h_{1 t}^{2}$ to follow an integrated GARCH model with no constant term in the conditional variance equation:

$$
\begin{aligned}
& h_{1 t}^{2}=a_{11} u_{t-1}^{2}+\left(1-a_{11}\right) h_{1, t-1}^{2} \\
& h_{2 t}^{2}=a_{02}+a_{12} u_{t-1}^{2}+b_{12} h_{2, t-1}^{2} .
\end{aligned}
$$

Working with non-negative state variables implies the necessity of a restriction on the sign of 
$\delta$. From the above discussion it comes out that the weight $w_{t-d}$ reaches its minimum value of $(1+\exp (\gamma \delta))^{-1}$ when $h_{t-d}=0$. Allowing negative values of $\delta$ amounts to constrain the weight of the first volatility component, which is intended to be associated with turbulent periods, to be greater than $1 / 2$ even when $h_{t-d}=0$. For this reason we impose the further restriction $\delta>0$.

\section{$3 \quad$ Likelihood inference and volatility prediction}

Inference for the model (1)-(5) does not suffer from the difficulties affecting other alternatives such as RS-GARCH models. In particular, deriving the prediction error decomposition form of the log-likelihood function is straightforward:

$$
\ell(u ; \boldsymbol{\theta})=\sum_{t=1}^{T} \log f\left(u_{t} h_{t}^{-1} ; \eta\right)-\sum_{t=1}^{T} \log h_{t}
$$

where $u=\left(u_{1} u_{2} \ldots u_{T}\right), f(. ; \eta)$ denotes the probability density function of the standardized error $z_{t}$, which may be indexed by a scalar parameter $\eta$, and $\boldsymbol{\theta}=\left(\boldsymbol{\beta}^{\prime} ; \mathbf{v}^{\prime} ; \mathbf{w}^{\prime} ; \eta\right)^{\prime}$ where $\mathbf{v}$ and $\mathbf{w}=(\gamma, \delta)^{\prime}$ are vectors collecting the unknown parameters in the volatility components and in the weight function $w($.$) , respectively. The log-likelihood function in (9) can be easily$ maximized by resorting to standard numerical procedures.

If we are interested in volatility prediction different considerations apply to one-step and multi-step ahead volatility predictions. In particular, if the forecast horizon $h$ is such that $h \leq d, h$-steps ahead volatility predictions can be computed analytically and the associated predictor is given by

$$
E\left(h_{T+j}^{2} \mid I^{T}\right)=\hat{h}_{T, j}^{2}=w_{T+j-d} \hat{h}_{T, j ; 1}^{2}+\left(1-w_{T+j-d}\right) \hat{h}_{T, j ; 2}^{2}
$$

where $\hat{h}_{T, j ; i}^{2}=E\left(h_{i, T+j}^{2} \mid I^{T}\right)$, for $i=1,2$. If the volatility components are assumed to follow a GARCH process, analytical expressions for the predictors $\hat{h}_{T, j ; i}^{2}$ can be obtained using the formulas given in Baillie and Bollerslev (1992). Differently, if $j>d$, deriving an analytical predictor becomes a more difficult task since the weights $w_{T+j-d}$ depend on future information, leading to the following expression:

$$
\hat{h}_{T, j}^{2}=E\left[w_{T+j-d} h_{T+j, 1}^{2} \mid I^{T}\right]+E\left[\left(1-w_{T+j-d}\right) h_{T+j, 1}^{2} \mid I^{T}\right] .
$$

So, if $j \leq d$, the volatility predictor is a linear combination of the predictors associated with each volatility component while, for $j>d$, this relationship becomes non-linear. 
The predictor in (11) can be evaluated by Monte Carlo simulation from the estimated model. However, this approach does not account for parameter uncertainty. Alternatively, it is possible to resort to the Bayesian approach in order to obtain an estimate of the predictive density of returns which is integrated over the admissible parameter space. This issue is dealt with in the next section.

In order to assess the practical relevance of this issue, it is worth discussing the value typically assumed for the delay $d$. The value of $d$ is expected to depend on the data collection frequency. However, if the model is fitted to daily data, it is reasonable to expect relatively low values of $d(d \leq 5)$. Hence, the generation of medium (e.g. weekly) and long-term (e.g. monthly) predictions of volatility will in general require to compute the expectation in (11). This is a relevant problem for risk managers, since long-term volatility predictions are required for the computation of some widely used risk measures such as VaR and ES. For example, the Basle Committee (1996) specifies a multiple of three times the $99 \%$ confidence 10-day VaR as minimum regulatory market risk capital. Also, the Risk Metrics Group (1999) suggests that the forecast horizon should reflect an institution typical holding period: "banks, brokers, and hedge funds tend to look at a 1-day to 1-week worst-case forecast, while longer-term investors, like mutual and pension funds, may consider a 1-month to 3-month time frame. Corporations may use up to an annual horizon for strategic scenario analysis".

\section{Bayesian inference for WGARCH models}

The complexity of GARCH models renders the derivation of analytical Bayesian inference results an insurmountable challenge. Hence the application of simulation based techniques is required. In order to draw a sample from the posterior distribution of the full parameter vector $\boldsymbol{\theta}$, we implement a Gibbs sampling algorithm with blocks given by $\boldsymbol{\theta}_{1}=\boldsymbol{\beta}$ and $\boldsymbol{\theta}_{2}=\left(\mathbf{v}^{\prime} ; \mathbf{w}^{\prime} ; \eta\right)^{\prime}$. For a given prior $\pi(\boldsymbol{\beta})$, the conditional posterior of $\boldsymbol{\beta}$ is given by

$$
\varphi\left(\boldsymbol{\beta} \mid \boldsymbol{\theta}_{2}, I^{T}\right) \propto \pi(\boldsymbol{\beta}) \prod_{t=1}^{T} f\left(r_{t} \mid \boldsymbol{\theta}, I^{t-1}\right)
$$

where $f($.$) indicates the density of r_{t}$. Since direct sampling from $\varphi\left(\boldsymbol{\beta} \mid \boldsymbol{\theta}_{2}, Y^{T}\right)$ is not feasible, we use the Metropolis-Hastings algorithm (Hastings, 1970), choosing a $k$-dimensional multivariate normal distribution as a proposal. The mean and variance of the proposal density are set equal to the maximum likelihood estimate and the inverse of the associated observed 
information matrix, respectively. Assuming prior independence, $\pi(\boldsymbol{\beta})$ is factorized as the product of $k$ uniform marginal densities. At the $(j+1)$-th iteration, we first generate a $(r \times 1)$ pseudo-random vector from the proposal, $z^{(j+1)} \sim \iota(z)$, and compute

$$
p=\min \left\{\frac{\varphi\left(z^{(j+1)}\right)}{\varphi\left(\beta^{(j)}\right)} \frac{\iota\left(z^{(j)}\right)}{\iota\left(\beta^{(j+1)}\right)}, 1\right\} .
$$

Then, we accept $\beta^{(j+1)}=z^{(j+1)}$, with probability $p$, and take $\beta^{(j+1)}=\beta^{(j)}$, with probability $1-p$.

Similarly, given a prior density $\pi\left(\boldsymbol{\theta}_{2}\right)$, the conditional posterior density of the parameter vector $\boldsymbol{\theta}_{2}$ is given by:

$$
\varphi\left(\boldsymbol{\theta}_{2} \mid \beta, I^{T}\right) \propto \pi\left(\boldsymbol{\theta}_{2}\right) \prod_{t=1}^{T} f\left(r_{t} \mid \boldsymbol{\theta}, I^{t-1}\right) .
$$

To simulate from the density in (14) we use the griddy Gibbs sampler. This algorithm has been originally proposed by Ritter and Tanner (1992) to solve a bivariate problem while Bauwens and Lubrano (1998) have successively applied it to the estimation of an asymmetric GARCH type model including seven parameters. Let us denote by $\boldsymbol{\theta}_{2}^{(j)}$ the value of the parameter vector sampled at the $j$-th iteration. At iteration $j+1$, a draw from the conditional posterior of $\boldsymbol{\theta}_{2}$ is generated through the following steps:

1. Let $\mathbf{v}_{-1}$ be the vector of volatility parameters excluding its first element $a_{01}$. Then, use (14) to evaluate $\kappa\left(a_{01} \mid \boldsymbol{\beta}^{j}, \mathbf{v}_{-1}^{j}, \mathbf{w}^{j}, I^{T}\right)$, which is the kernel of the conditional posterior density of $a_{01}$ given $\boldsymbol{\beta}, \mathbf{w}$ and $\mathbf{v}_{-1}$ sampled at iteration $j$, over a grid $\left(a_{01}^{1}, a_{01}^{2}, \ldots, a_{01}^{G}\right)$. The calculated values form the vector $G_{\kappa}=\left(\kappa_{1}, \ldots, \kappa_{G}\right)$ with $\kappa_{i}(i=1, \ldots, G)$ being the kernel evaluated at the $i$-th grid point.

2. By a deterministic integration rule using $M$ points, compute

$$
G_{\Phi}=\left(0, \Phi_{2}, \ldots, \Phi_{G}\right)
$$

with

$$
\Phi_{i}=\int_{a_{01}^{1}}^{a_{01}^{i}} \kappa\left(a_{01} \mid \boldsymbol{\beta}^{j}, \mathbf{v}_{-1}^{j}, \mathbf{w}^{j}, I^{T}\right) d a_{01} \quad i=2, \ldots, G .
$$

3. Simulate $u \sim U\left(0, \Phi_{G}\right)$ and invert $\left.\Phi\left(a_{01} \mid \boldsymbol{\beta}^{j}, \mathbf{v}_{-1}^{j}, \mathbf{w}^{j}, I^{T}\right)\right)$ by numerical interpolation to obtain a draw $\left.a_{01}^{(j+1)} \sim \varphi\left(a_{01} \mid \boldsymbol{\beta}^{(j)}\right), \mathbf{v}^{(j)}{ }_{-1}, \mathbf{w}^{(j)}, I^{T}\right)$. 
4. Repeat steps 1-3 for all the other parameters in $\boldsymbol{\theta}_{2}$.

The implementation of the griddy Gibbs sampler requires the definition of suitable integration intervals for each of the elements in $\boldsymbol{\theta}_{2}$. The definition of the integration intervals plays a critical role in the procedure and so their determination must be made carefully. The values of the integration bounds for each parameter are usually tentatively specified and adjusted in order to cover the region of the parameter space over which the posterior is relevant. The prior distributions are assumed to be uniform over the chosen intervals for all the parameters except for $\gamma$, the slope coefficient of the weight function.

Following Lubrano (2001), choosing a uniform prior for this parameter leads to a nonintegrable posterior distribution. A similar problem arises for the degrees of freedom parameter $\nu$ if the errors are assumed to follow a Student's $t$ distribution, as shown in Bauwens and Lubrano (1998). In both cases, one possible solution is to assume an uniform prior restricted over a finite interval where the restriction on the prior domain is automatically implied by the use of the griddy Gibbs sampler. An alternative choice is to use a truncated Cauchy density as a prior, which gives:

$$
\pi(\nu) \propto\left(1+\nu^{2}\right)^{-1} \quad \pi\left(\gamma_{i}\right) \propto\left(1+\gamma^{2}\right)^{-1} .
$$

Bauwens and Lubrano (1998) document a very long tail for $\nu$ when a flat prior is used while Lubrano (2001) successfully applies this solution to the estimation of a ST-GARCH model with a logistic transition function. So, our preference is for a half-Cauchy prior since we expect this choice to limit the impact on the posterior results of the chosen integration interval.

\section{Bayesian prediction of VaR and ES}

VaR and ES are two popular measures of market risk commonly used by researchers and risk managers. If we let $R_{T+h}=\sum_{i=1}^{h} r_{T+i}$ be the $h$-period $(h>0)$ aggregated return, at time $T$ the $h$-period VaR at the $100(1-\alpha) \%$ confidence level, indicated as $V a R_{T, h}^{(\alpha)}$, can be defined as the order $\alpha$ quantile of the conditional distribution of $R_{T+h}$ conditional on information at the time of prediction $T:^{2}$

$$
P\left(R_{T+h}<\operatorname{Va} R_{T, h}^{(\alpha)} \mid I^{T}\right)=\alpha .
$$

\footnotetext{
${ }^{2}$ Our definition of VaR differs from that commonly used in risk management practice since, as an estimate of VaR, we consider the relevant empirical quantile of the predictive distribution of returns taken with its sign.
} 
Hence the value of the $h$-day ahead ES at the $100(1-\alpha \%)$ confidence level is defined as

$$
E S_{T, h}^{(\alpha)}=E\left(R_{T+h} \mid R_{T+h}<\operatorname{Va} R_{T, h}^{(\alpha)}, I^{T}\right) .
$$

Accordingly, the one-period VaR is just the order $\alpha$ quantile of the conditional distribution of $r_{T+1}$ given $I^{T}$.

Despite the increasing popularity of VaR, following the Basle Agreement on Banking Supervision (1996), it can been shown that, differently from ES, VaR is not a coherent measure of risk since it does not satisfy the sub-additivity property (Artzner et al., 1999; Acerbi and Tasche, 2002). In the last decade we assisted to the flourishing of a rich literature concerning the estimation of VaR and ES. Nevertheless, little attention has been paid to the development of approaches able to account for the impact of parameter uncertainty on estimated risk measures. This problem is addressed by Christoffersen and Goncalves (2005) who suggest using residual bootstrap to evaluate confidence intervals for VaR and ES. Their approach is however limited to $\operatorname{GARCH}(1,1)$ processes and one-period VaR. A closely related algorithm based on residual bootstrap is applied by Pascual et al. (2006) in order to estimate predictive intervals for the volatility of a $\operatorname{GARCH}(1,1)$ process. The Bayesian approach offers a convenient framework for the estimation of VaR and ES. $V a R_{T, h}^{(\alpha)}$ is defined as the order $\alpha$ quantile of the predictive density $f\left(R_{T+h} \mid I^{T}\right)$. In general, assuming that an analytical expression for $f\left(R_{T+h} \mid I^{T}, \boldsymbol{\theta}\right)$ is available, this density can be calculated by solving the integral

$$
f\left(R_{T+h} \mid I^{T}\right)=\int f\left(R_{T+h} \mid I^{T}, \boldsymbol{\theta}\right) \varphi\left(\boldsymbol{\theta} \mid I^{T}\right) d \boldsymbol{\theta} .
$$

Alternatively, assuming we can sample from the posterior $\varphi\left(\boldsymbol{\theta} \mid I^{T}\right)$, e.g. using the Gibbs sampler described in the previous section, a sample from the density in (18) can be drawn by repeating $N$ times the following steps:

1. Simulate $\boldsymbol{\theta}^{(j)}$ from $\varphi\left(\boldsymbol{\theta} \mid I^{T}\right)$.

2. Simulate $R_{T+h}^{(j)}$ from $f\left(R_{T+h} \mid I^{T}, \boldsymbol{\theta}^{(j)}\right)$ by simulating successively, for $k=1$ to $h, r_{T+k}^{(j)}$ from $f\left(r_{T+k} \mid I^{T}, r_{T+k-1}^{(j)}, \ldots, r_{T+1}^{(j)}, \boldsymbol{\theta}^{(j)}\right)$ and computing $R_{T+h}^{(j)}$ as $\sum_{k=1}^{h} r_{T+k}^{(j)}$.

Step 2 amounts to generate a trajectory of $h$ one-period future returns and aggregating them to obtain the $h$-period return.

An estimate of $V a R_{T, h}^{(\alpha)}$ is then obtained by computing the order $\alpha$ quantile of the sample of size $N$ drawn from $f\left(R_{T+h} \mid I^{T}, \boldsymbol{\theta}\right)$. Conditioning on the estimated VaR, an estimate of 
$E S_{T, h}^{(\alpha)}$ can be computed as

$$
\widehat{E S}_{T, h}^{(\alpha)}=\frac{1}{\#\left(R_{T+h, j}<V a R_{T, h}^{(\alpha)}\right)} \sum_{j: R_{T+h, j}<V a R_{T, h}^{(\alpha)}} R_{T+h}^{(j)},
$$

which is the mean of the sampled returns falling below the estimated VaR. So estimates of $\mathrm{VaR}$ and ES for relatively long holding periods are obtained in a straightforward manner as a by-product of the Gibbs sampling algorithm. This way of computing VaR and ES has two important advantages. First, it naturally accounts for parameter uncertainty since the predictive densities of returns are integrated over the parameter space. Second, long term predictions of volatility and related risk measures can be easily obtained by simulation independently of the model complexity.

\section{An application to daily $S \& P 500$ returns}

In this section, we present an application to a time series of daily (percentage) log-returns on the $S \& P 500$ stock market index. The observation period goes from January 5, 1971 to December 29, 2006 for a total of 9086 observations (figure 1). The data are characterized by a strong kurtosis and a remarkable negative skewness (table 1). The value of the LjungBox $Q$-statistics provides evidence in favour of the presence of a significant autocorrelation structure in the returns as well as in the squared returns series. Moreover, visual inspection of the sample correlogram of the squared returns reveals a highly persistent autocorrelation pattern (figure 2). In order to account for these features we model the returns $r_{t}$ by a first order autoregressive model whose residuals follow a WGARCH model of order $(1,1)$ :

$$
\begin{aligned}
r_{t} & =\phi_{0}+\phi_{1} r_{t-1}+u_{t} \\
u_{t} & =h_{t} z_{t}
\end{aligned}
$$

where $z_{t} \stackrel{i i d}{\sim}(0,1)$ and $h_{t}^{2}$ is defined as in (4) with $p=q=1$. The value of the delay parameter $d$ has been set equal to 1 .

The series has been divided into two subseries including observations from 1 to 8500 and from 8501 to the end of the observation period, respectively. The first subseries has been used for model estimation while the second one has been kept for out of sample forecast 
Table 1: Descriptive statistics and Ljung-Box $Q$-statistics for the S\&P 500 returns $\left(Q_{r}().\right)$ and squared returns $\left(Q_{r^{2}}().\right)$. Values in brackets are p-values.

\begin{tabular}{cccccccc}
\hline mean & s.d. & min. & max. & skew. & kur. & $Q_{r}(10)$ & $Q_{r^{2}}(10)$ \\
\hline 0.0302 & 0.9906 & -22.8997 & 8.7089 & -1.4419 & 38.6458 & $\begin{array}{l}51.771 \\
(0.0000)\end{array}$ & $\begin{array}{l}656.55 \\
(0.0000)\end{array}$ \\
\hline
\end{tabular}

evaluation. In order to estimate the joint posterior of the $\operatorname{AR}(1)-\operatorname{WGARCH}(1,1)$ defined in equations (20)-(21) we have implemented the Gibbs sampler described in section 4 under two different distributional assumptions for $z_{t}$, normal and Student's t.

As a proposal for the Metropolis-Hastings step of the algorithm we have chosen a bivariate normal. The covariance matrix estimated by the observed information matrix has been multiplied by an inflation factor equal to 1.2 to allow for tails heavier than those implied by the asymptotic distribution of the maximum likelihood estimator.

In the implementation of the griddy Gibbs sampler for the volatility model parameters, the integration intervals used for the estimation, as it is usual practice, have been selected by a trial and error procedure aimed at avoiding sharp truncations in the tails of the marginal posterior distributions while still preserving the positivity of the estimated conditional variance and its components.

For the normal model, 10000 iterations of the algorithm have been performed. The convergence of the chain has been assessed by using cumsum diagrams. A simple visual inspection of the plots suggests that, for the normal model (figure 3), convergence is likely to be achieved after iteration 5000. Hence, only the second half of the chain is used for inference while the first 5000 draws are discarded. Differently, for the $t$ model (figure 4), since the chain is converging more slowly than in the normal case, it is necessary to increase the number of iterations from 10000 to 15000 . The first 10000 draws have then been used as burn-in period for the sampler.

The posterior means and standard deviations based on the adjusted samples are reported in table 2. In general, the estimated persistence of the first volatility component (figures $5 \mathrm{a}$ and $6 \mathrm{a})$, measured in terms of the sum $\left(a_{11}+b_{11}\right)$, is substantially lower than the corresponding estimate obtained for the second component (figures $5 \mathrm{~b}$ and $6 \mathrm{~b}$ ). The persistence decrease is higher for the model with $t$ errors, 0.64 versus 0.98 , than for the normal, 0.84 versus 0.99 . 
Other important differences between the two volatility components arise if we consider the value of the intercept and of the GARCH parameter which turn out to be higher for the first component, that is the one associated with turbulent periods. Also, in the normal case the value of the estimated GARCH coefficient is much higher than for the $t$ model reflecting a higher sensitivity to recent shocks. So it follows that in turbulent periods the volatility tends to be less persistent and more sensitive to recent shocks. Differently, in tranquil periods volatility is highly persistent and less sensitive to shocks. In other words, its variation tends to be mainly driven by long run factors.

Table 2: Posterior means and standard deviations (in brackets) for the normal WGARCH, $t$-WGARCH, normal GARCH and $t$-GARCH models

\begin{tabular}{ccccc}
\hline & $\mathrm{WG}_{n}$ & $\mathrm{WG}_{t}$ & $\mathrm{G}_{n}$ & $\mathrm{G}_{t}$ \\
\hline$\phi_{0}$ & 0.0370 & 0.0390 & 0.0401 & 0.0395 \\
& $(0.0087)$ & $(0.0089)$ & $(0.0093)$ & $(0.0089)$ \\
$\phi_{1}$ & 0.0854 & 0.0833 & 0.0955 & 0.0831 \\
& $(0.0110)$ & $(0.0119)$ & $(0.0125)$ & $(0.0121)$ \\
\hline$a_{01}$ & 0.4433 & 0.3872 & 0.0090 & 0.0049 \\
& $(0.2406)$ & $(0.2804)$ & $(0.0019)$ & $(0.001146)$ \\
$a_{11}$ & 0.3781 & 0.1091 & 0.0685 & 0.0405 \\
& $(0.1024)$ & $(0.0615)$ & $(0.0059)$ & $(0.0043)$ \\
$b_{11}$ & 0.4642 & 0.5332 & 0.9242 & 0.9397 \\
& $(0.1030)$ & $(0.2112)$ & $(0.0067)$ & $(0.0062)$ \\
$a_{02}$ & 0.0050 & 0.0032 & & \\
& $(0.0022)$ & $(0.0018)$ & & \\
$a_{12}$ & 0.0440 & 0.0398 & & \\
& $(0.0104)$ & $(0.0082)$ & & \\
$b_{12}$ & 0.9495 & 0.9429 & & \\
& $(0.0104)$ & $(0.0082)$ & & \\
$\gamma$ & 6.604 & 2.737 & & \\
& $(2.9894)$ & $(2.080)$ & & \\
$\delta$ & 1.449 & 2.598 & & \\
& $(0.1079)$ & $(1.229)$ & & \\
\hline \multirow{2}{*}{$\nu$} & & 8.218 & & 8.061 \\
& & $(0.9338)$ & & $(0.6739)$ \\
\hline
\end{tabular}

Figures $5 \mathrm{c}$ and $6 \mathrm{c}$ report the time plots of the weight functions $w($.$) evaluated at the$ estimated posterior means assuming normal and $t$ errors, respectively. In both cases, as expected, in highly volatile periods the first component virtually excludes the other while the opposite happens as the market moves back to a tranquil state. High volatility periods, 
however, are differently identified within the normal and $t$ models. In the $t$ model, the estimate of the threshold parameter $\delta$ turns out to be higher than for the normal model, leading to a substantial reduction of the average weight of the high volatility component. This implies that the model completely switches to the high volatility regime only in the period immediately following the "black Monday" stock market crash in October 1987.

Figures 7 and 8 report the smoothed empirical densities ${ }^{3}$ of the samples drawn from the posteriors of the conditional mean parameters $\phi_{0}$ and $\phi_{1}$. The estimated marginal posterior densities of the volatility model parameters computed by the griddy Gibbs sampler have been reproduced in figures 9 and 10, respectively. As expected the marginal posterior of the slope coefficient of the logistic function $\gamma$ is positively skewed and characterized by a very long tail. Nevertheless, its mode is far away from zero providing further evidence in favour of the time varying weights model.

Next, we have applied the estimated WGARCH models for predicting VaR and ES at different horizons $(h=1,5,10,15,20)$ and for different confidence levels $(\alpha=0.10,0.05,0.025,0.01)$. Also, following Giot and Laurent (2005), long as well as short trading positions have been considered. VaR and ES predictions have been generated using the simulation based procedure described in section 5. The performance of the estimated AR-WGARCH models has been compared to those of two different $\mathrm{AR}(1)$ models with $\operatorname{GARCH}(1,1)$ errors charaterized by Student's $t$ and normal innovations, respectively. Again, inference on the model parameters has been conducted by the same Bayesian approach described in section 4 . The estimated posterior means and standard deviations are reported in table 2.

In order to assess the quality of VaR predictions we have used the likelihood ratio statistic proposed by Kupiec (1995) for testing the hypothesis of correct unconditional coverage. By means of a binomial likelihood, the number of observed VaR exceptions is compared to the expected number of VaR exceptions under the hypothesis of correct coverage. The empirical coverages and the associated $p$-values are reported in table 3. For long trading positions, if a 1 day holding period is considered, the models with normal errors tend to perform better but they are outperformed by their counterparts with $t$ errors as the holding period increases. Overall, the WGARCH model with the $t$ errors appears to offer the best trade-off between short and medium-long term predictive ability. A different picture arises as we move to con-

\footnotetext{
${ }^{3}$ The smoothed estimates have been computed by means of an Epanechnikov kernel estimator.
} 
sider short positions. All the models perform satisfactorily if we consider a 1 day holding period but none of them appears to be effective in estimating VaR for longer holding periods. Differently from VaR, backtesting ES predictions is not a standard problem and the literature on this topic is still under development. In this paper, to assess the quality of ES predictions we have used the censored likelihood ratio test statistic proposed by Berkowitz (2001). Let $f_{t}\left(y_{t+h}\right)=f\left(y_{t+h} \mid I^{t}\right)$ be the $h$-step ahead predictive density of $y_{t}$ and $F_{t}\left(y_{t+h}\right)$ be the associated cumulative distribution function (cdf). By proposition 1 in Berkowitz (2001), the transformed series

$$
x_{t+h}=\Phi^{-1}\left(\int_{-\infty}^{y_{t+h}} f_{t}(r) d r\right)=\Phi^{-1}\left(F_{t}\left(y_{t+h}\right)\right)
$$

where $\Phi($.$) denotes the standard normal cdf, is distributed as a sequence of iid \mathrm{N}(0,1)$ random variables. The accuracy of our prediction model for an arbitrarily defined variable $y_{t}$ can then be tested by checking for deviations from the standard normality assumption in the series

$$
\hat{x}_{t+h}=\Phi^{-1}\left(\int_{-\infty}^{y_{t+h}} \hat{f}_{t}(r) d r\right)=\Phi^{-1}\left(\hat{F}_{t}\left(y_{t+h}\right)\right)
$$

where the hat denotes an estimated value. Since we are only interested in the tail behaviour of the predictive density, in order to assess the accuracy of a series of ES predictions, it is possible to define a likelihood ratio test statistic based on a censored normal likelihood with censoring occurring at the relevant percentile of the distribution of $x_{t}$

$$
x_{\alpha}=\Phi^{-1}(\alpha),
$$

where $\alpha$ is the confidence level for VaR estimation. Define

$$
\hat{x}_{t}^{*}=\left\{\begin{array}{ll}
x_{\alpha} & \text { if } \hat{x}_{t} \geq x_{\alpha} \\
\hat{x}_{t} & \text { if } \hat{x}_{t}<x_{\alpha}
\end{array} .\right.
$$

for $t=T+1, \ldots, T+H$ where $H$ is the length of the forecasting period. The censored $\log$-likelihood function for the estimation of $\mu=E\left(\hat{x}_{t}\right)$ and $\sigma=\operatorname{var}\left(\hat{x}_{t}\right)^{1 / 2}$ is given by:

$$
\ell\left(\hat{x}^{*} \mid \mu, \sigma\right)=\sum_{\hat{x}_{t}^{*}<x_{\alpha}}\left[-\frac{1}{2} \log \left(2 \pi \sigma^{2}\right)-\frac{1}{2 \sigma}\left(\hat{x}_{t}^{*}-\mu\right)^{2}\right]+\sum_{\hat{x}_{t}^{*}=x_{\alpha}} \log \left(1-\Phi\left(\frac{x_{\alpha}-\mu}{\sigma}\right)\right)
$$

Under the null of correct specification, $\hat{x}_{t} \underset{i i d}{\sim} N(0,1)$. Hence, the associated test statistic is

$$
L R_{\text {tail }}=-2(\ell(0,1)-\ell(\hat{\mu}, \hat{\sigma}))
$$


The values of $\hat{\mu}$ and $\hat{\sigma}$ have been determined by numerical maximization of the log-likelihood in (22). Under the null, $L R_{\text {tail }}$ is asymptotically distributed as a $\chi_{2}^{2}$ random variable. A similar procedure can be defined for the right tail of the distribution (short positions).

Even if a closed form expression for the predictive density is not available, we can simulate from it using the Gibbs sampler. Namely, let $R_{t+h}^{(j)}, j=1, \ldots, N$, be a sample from $\hat{f}\left(R_{t+h} \mid I^{t}\right)$. We can compute the value of the empirical cdf at any sample point as

$$
\hat{F}\left(R_{t+h}^{(j)} \mid I^{t}\right)=\frac{\operatorname{rank}\left(R_{t+h} \mid R_{t+h}^{(1)}, \ldots, R_{t+h}^{(N)}\right)}{N+1}
$$

where $R_{t+h}$ is the $h$-period ahead cumulated return at time $t$ and $\operatorname{rank}\left(x \mid y^{(1)}, \ldots, y^{(N)}\right)$ denotes the rank of $x$ in the sample $\left\{y^{(1)}, \ldots, y^{(N)}\right\}$. We can then apply the test statistic in (23) to the normal transformation of the empirical cdf. It must be stressed that the $L R_{\text {tail }}$ statistic does not allow to directly test the accuracy of the ES prediction but provides an assessment of the accuracy globally achieved in fitting the tails of the predictive density.

The results of the censored likelihood ratio test (table 4) are in line with what observed for VaR prediction. For a holding period of 1 day and for long positions, the $t$ GARCH model is outperformed by the normal WGARCH and GARCH models. Normal models, however, are not accurate at predicting ES for longer holding periods. Again, the WGARCH model with $t$ errors appears to offer a reasonable trade-off. It performs satisfactorily in predicting the ES for a 1 day holding period while still providing accurate longer term prediction of the ES. For what concerns short trading positions, all the models are sufficiently accurate in predicting ES 1 day ahead while, again, for longer holding periods none of the models considered performs satisfactorily. For holding periods $\geq 5$, we have not reported the value of the $L R_{\text {tail }}$ test for $\alpha=0.01$. In these cases, due to the highly conservative nature of the associated VaR estimates, only a reduced number of points was found to fall below the threshold $x_{0.01}$ in (22). Hence the test is likely to be not accurate since the available sample from $\hat{x}_{t}$ does not provide sufficient information for reconstructing its extreme tail behaviour.

\section{Concluding remarks}

The WGARCH model discussed in this paper allows to reproduce state dependent volatility dynamics without suffering from the limitations which typically complicate inference from other alternatives such as RS-GARCH models. 
To investigate the effectiveness of WGARCH models in standard risk management applications, we have presented an application of the proposed modelling strategy to the prediction of VaR and ES for a time series of daily returns on the S\&P 500. The empirical results show that the predictive performance of a WGARCH model with $t$ errors favourably compares with that of standard GARCH models. In order to further improve the ability of WGARCH models to reproduce the tail behaviour of asset returns, it could be of interest considering skewed error distributions such as the Skew $t$ distribution investigated by Bauwens and Laurent (2005). Finally, another important topic for future research is related to the investigation of the statistical properties of WGARCH models such as implied moments and volatility autocorrelation structure. 


\section{References}

Acerbi, C., Tasche, D. (2002) On the coherence of Expected Shortfall, Journal of Banking and Finance, 26(7), 1487-1503.

Artzner, P., Delbaen, F., Eber, J.-M., Heath, D. (1999) Coherent measures of risk, Mathematical Finance, 9(3), 203228.

Baillie, R.T., Bollerslev, T. (1992) Prediction in Dynamic Models with Time Dependent Conditional Variances, Journal of Econometrics, 52, 91-113.

Bank for International Settlements (1996) Basle Committee on Banking Supervision. Amendment to the Capital Accord to incorporate market risks.

Bauwens, L., Laurent, S. (2005) A new class of multivariate skew densities, with application to GARCH models, Journal of Business and Economic Statistics, 23(3), 346-354.

Bauwens, L., Lubrano, M. (1998) Bayesian inference on GARCH models using the Gibbs sampler,Econometrics Journal, 1, pages C23-C46.

Bauwens, L., Preminger, A., Rombouts, J. V. K. (2006) Regime switching GARCH models, CORE Discusion Paper, 2006/11.

Berkowitz, J. (2001) Testing density forecasts with applications to risk management, Journal of Business 83 Economic Statistics, 19, 4, 465-474.

Christoffersen, P., Goncalves, S. (2005) Estimation Risk in Financial Risk Management, Journal of Risk, 7, 1-28.

Ding, Z., Granger, C. W. J. (1996) Modeling volatility persistence of speculative returns: a new approach, Journal of Econometrics, 73, 185-215.

Engle, R. F., Lee, G. G. J. (1999) A Long-Run and Short-Run Component Model of Stock Return Volatility, in Cointegration, Causality, and Forecasting (Engle R. F. and White H., eds.), Oxford University Press.

Giot, P., Laurent, S. (2003) Value-at-Risk for long and short trading positions, Journal of Applied Econometrics,18, 641-664. 
Gray, S. (1996) Modeling the conditional distribution of interest rates as a regime- switching process, Journal of Financial Economics, 42, 27-62.

Haas, M., Mittnik, S., Paolella, M. S. (2004) A new approach to Markov-Switching GARCH models, Journal of Financial Econometrics, 2, 493-530.

Hamilton, J.D., Susmel, R. (1994) Autoregressive Conditional Heteroskedasticity and Changes in Regime Journal of Econometrics, 64, 307-333.

Hastings, W.K. (1970) Monte Carlo Sampling Methods Using Markov Chains and Their Applications, Biometrika, 57,1 97-109.

Jorion, P. (1997) Value at Risk: The New Benchmark for Controlling Market Risk, McGraw Hill, New York, US.

Kupiec, P. (1995) Techniques for verifying the accuracy of risk measurement models, Journal of Derivatives, 3, 73-84.

Lamoureux, C. G., Lastrapes, W. D. (1990) Persistence in variance, structural change and the GARCH model, Journal of Business and Economic Statistics, 8, 2225-234.

Lamoureux, C. G., Lastrapes, W. D. (1993) Forecasting stock returns variance: toward an understanding of stochastic implied volatilities, Review of Financial Studies, 8, 293-326.

Lubrano, M. (2001) Smooth transition GARCH models: a Bayesian approach, Recherches Economiques de Louvain, 67, 257-287.

Luukkonen, R. Saikkonen, P. and Terasvirta, T. (1988) Testing linearity against smooth transition autoregressive models, Biometrika, 75, 491-499.

Maheu, J. (2005) Can GARCH models capture long range dependence?, Studies in Nonlinear Dynamics $\&$ Econometrics, 9, No. 4, Article 1.

Mikosch, T., Starica, C. (2004) Nonstationarities in Financial Time Series, the LongRange Dependence, and the IGARCH Effects,Review of Economics and Statistics, 86, $378-390$.

Nelson, D. B. (1992) Filtering and forecasting with misspecified ARCH models. I: getting the right variance with the wrong model, Journal of Econometrics, 52, 61-90. 
Pascual, L., Romo, J., Ruiz, E. (2006) Bootstrap Prediction for Returns and Volatilities in GARCH Models, Computational Statistics 83 Data Analysis, 50, 2293-2312.

Risk Metrics Group (1999) Risk Management: A Practical Guide, www.riskmetrics.com. Ritter, C., Tanner, M. A. (1992) Facilitating the Gibbs Sampler: The Gibbs Stopper and the Griddy-Gibbs Sampler, Journal of the American Statistical Association, 87, 861-868. 


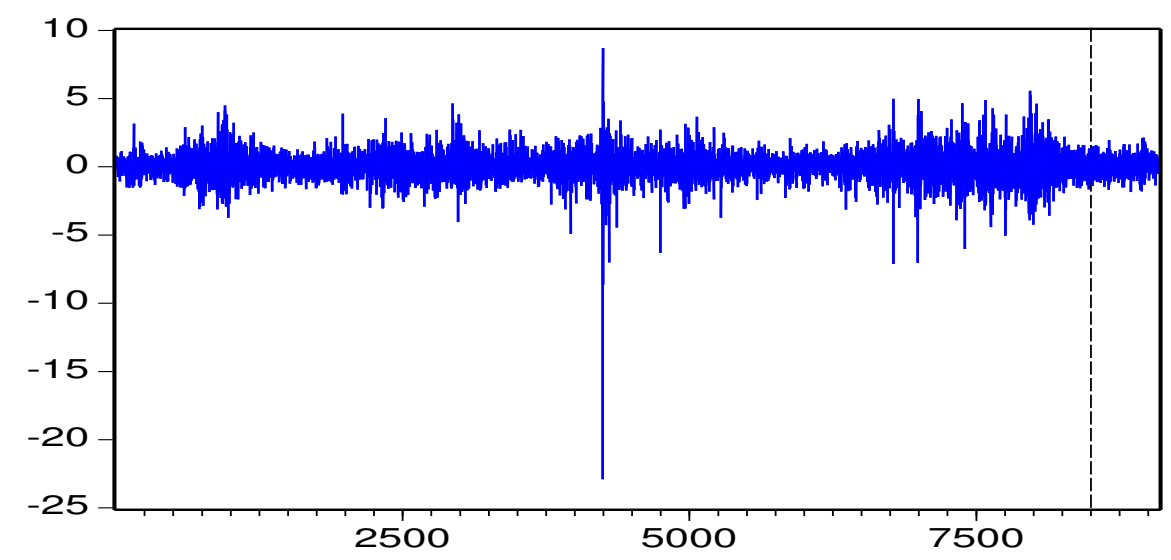

Figure 1: Daily returns on the S\&P 500 from from January 5th, 1971 to December 29th, 2006
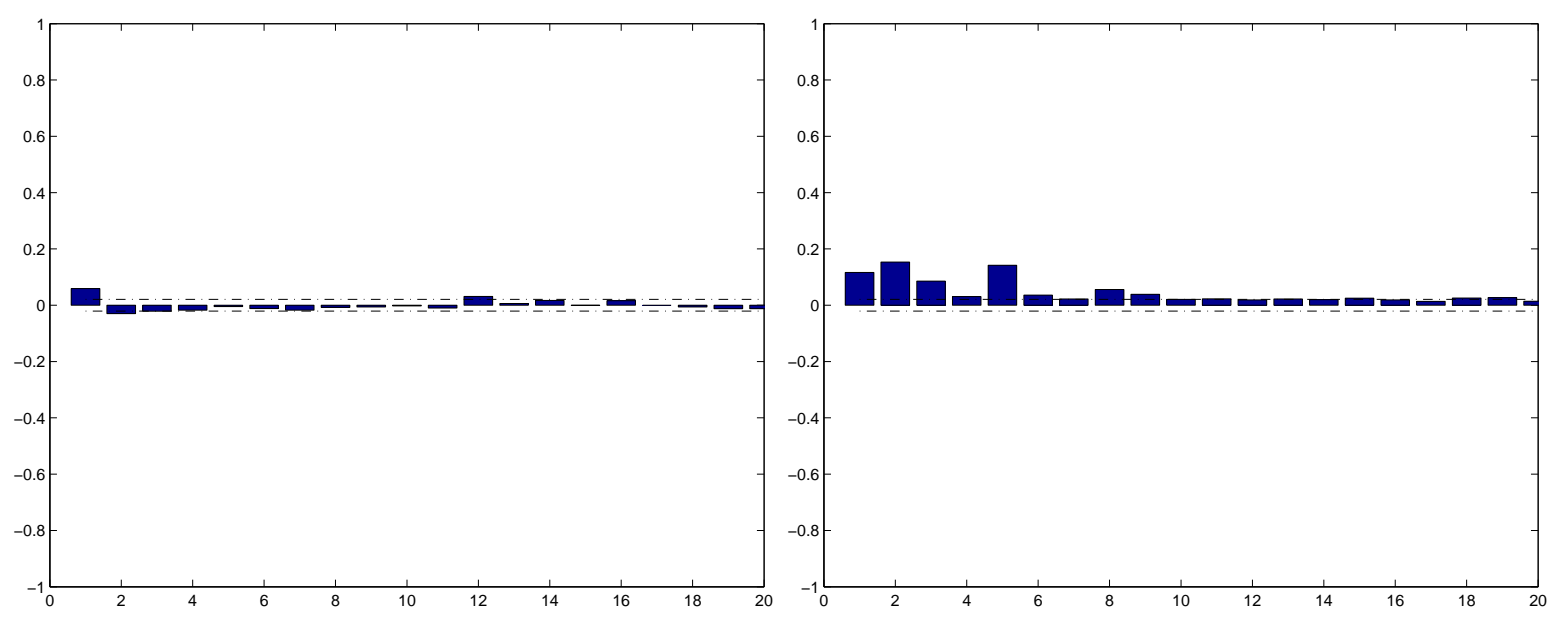

Figure 2: Sample autocorrelation function of S\&P 500 returns (left) and squared returns (right) from January 5th, 1971 to December 29th, 2006 


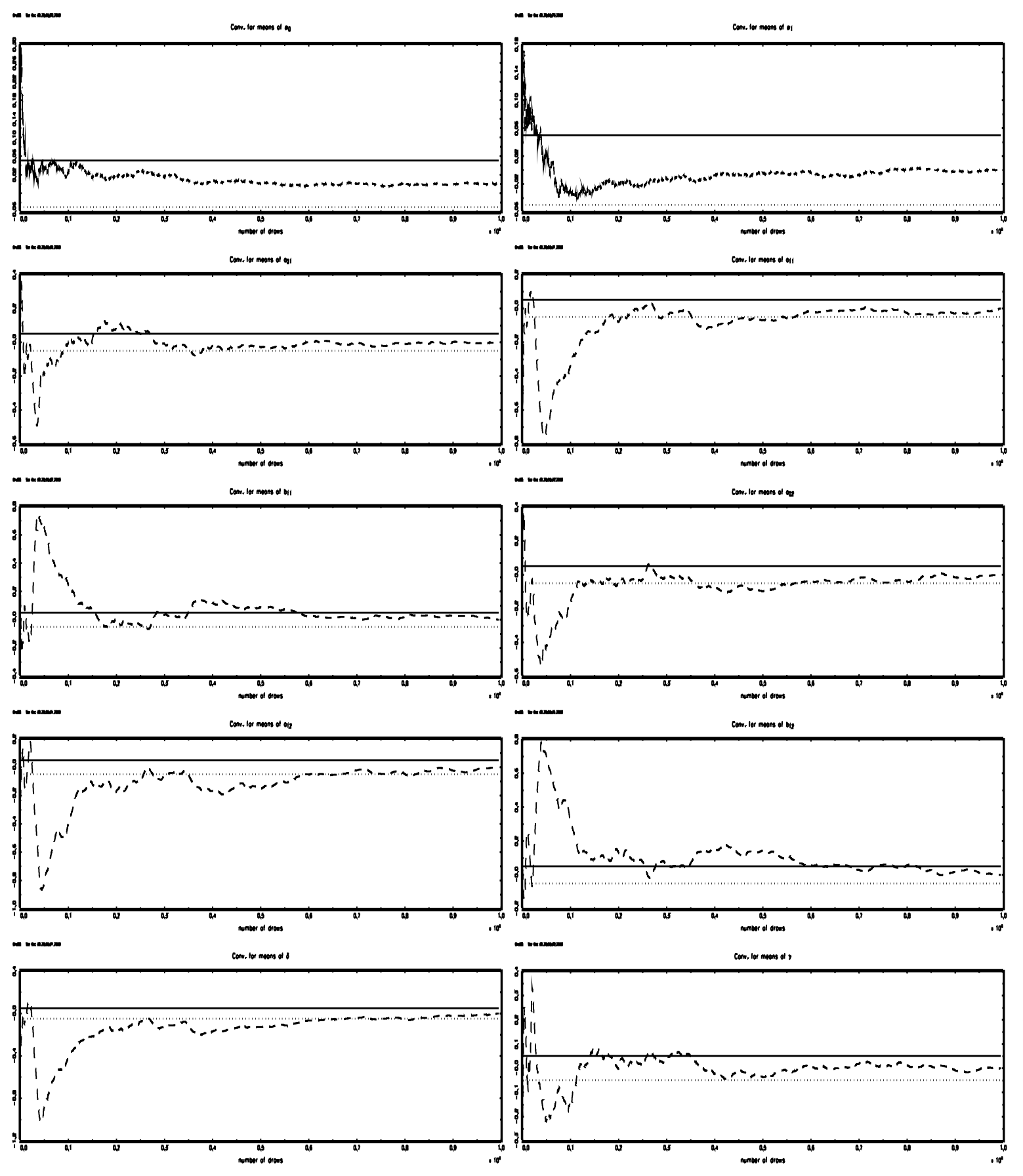

Figure 3: Cumsum diagrams with $\pm 5 \%$ bands for the normal WGARCH model. From left to right and from top to bottom: $\phi_{0}, \phi_{1}, a_{01}, a_{11}, b_{11}, a_{02}, a_{12}, b_{12}, \delta, \gamma$. 


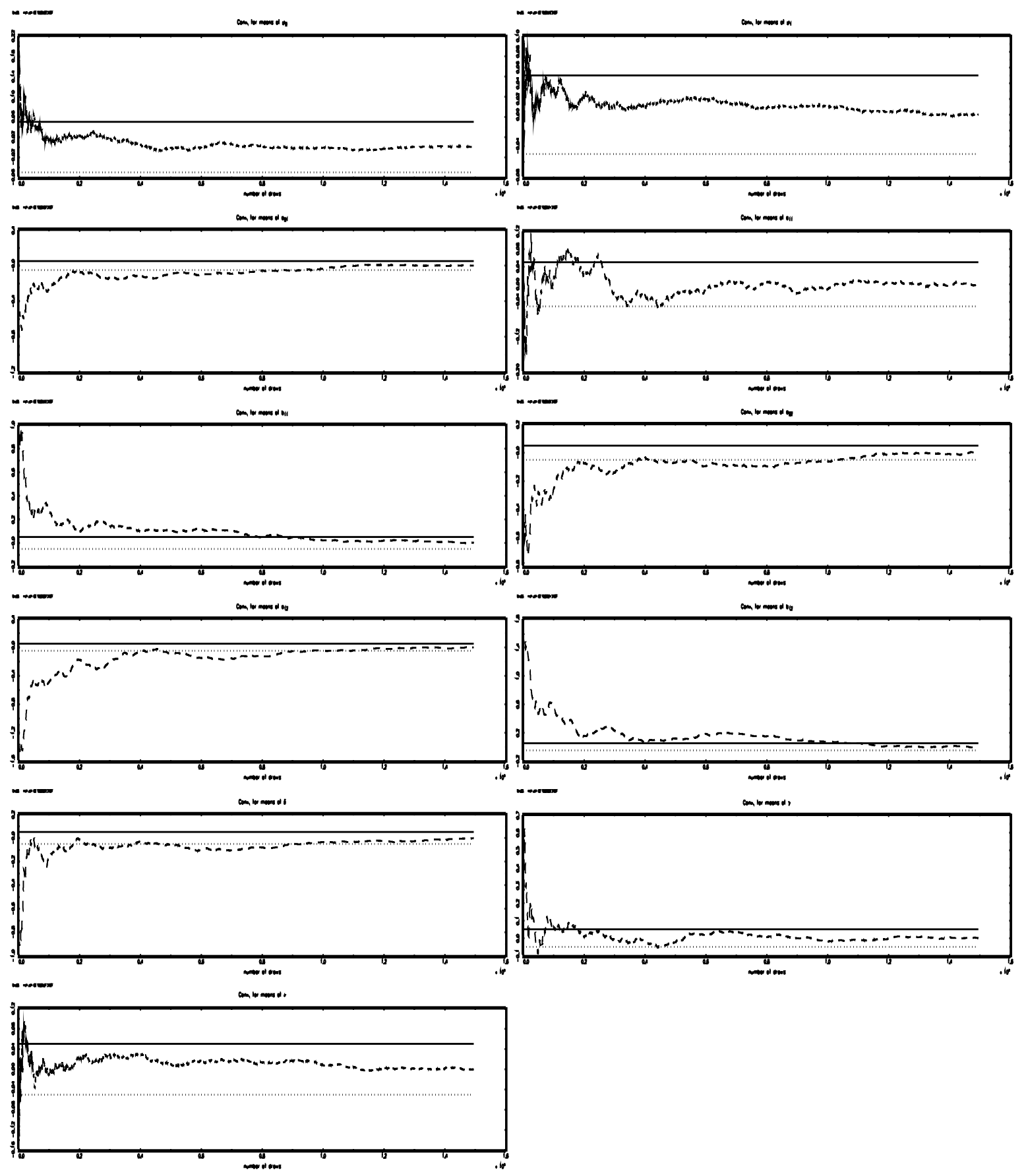

Figure 4: Cumsum diagrams with $\pm 5 \%$ bands for the $t$ WGARCH model. From left to right and from top to bottom: $\phi_{0}, \phi_{1}, a_{01}, a_{11}, b_{11}, a_{02}, a_{12}, b_{12}, \delta, \gamma, \nu$. 

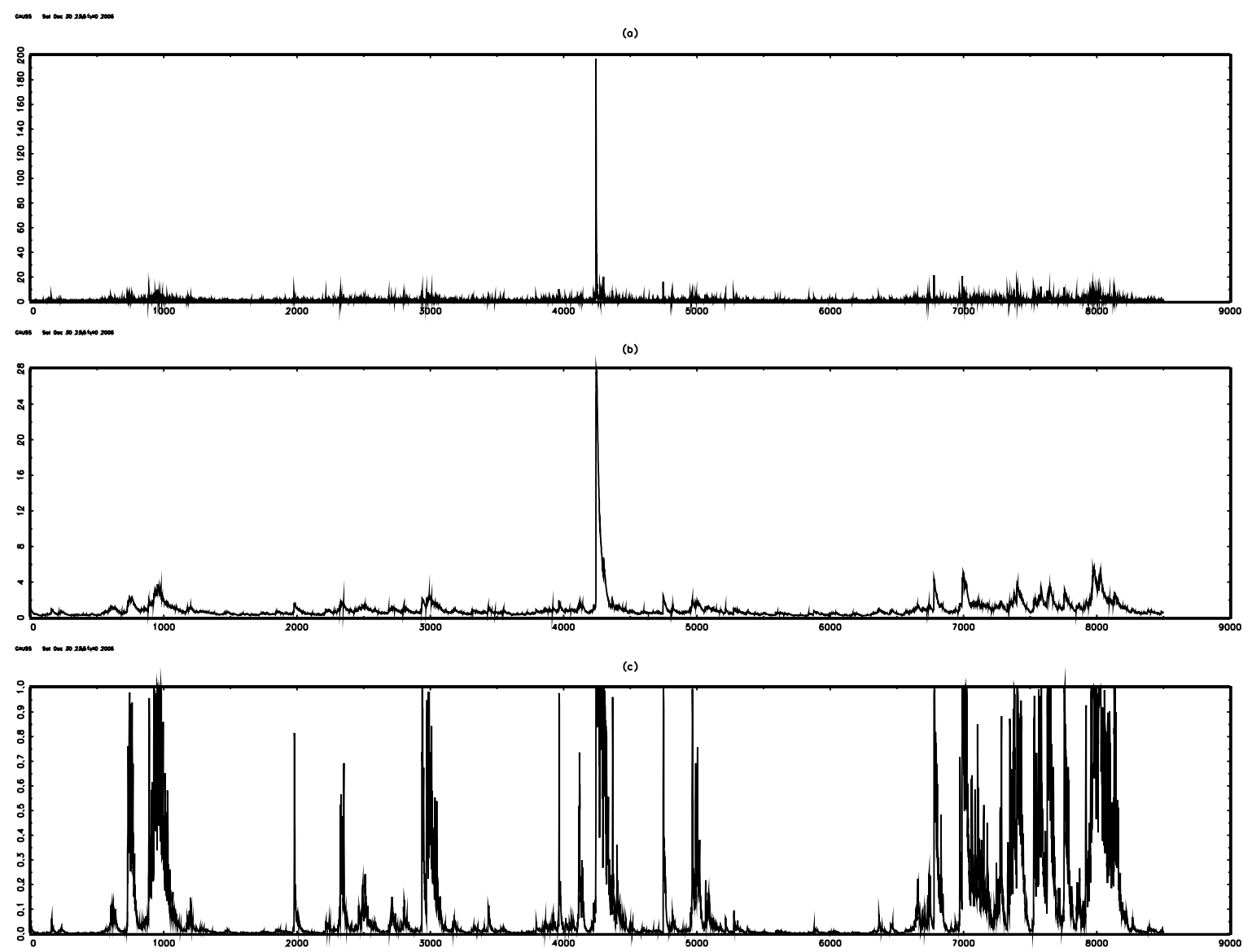

Figure 5: First volatility component $\left(h_{1 t}^{2}\right.$, a), second volatility component $\left(h_{2 t}^{2}, \mathrm{~b}\right)$, weights series $\left(w_{t}, c\right)$ from the normal WGARCH model 

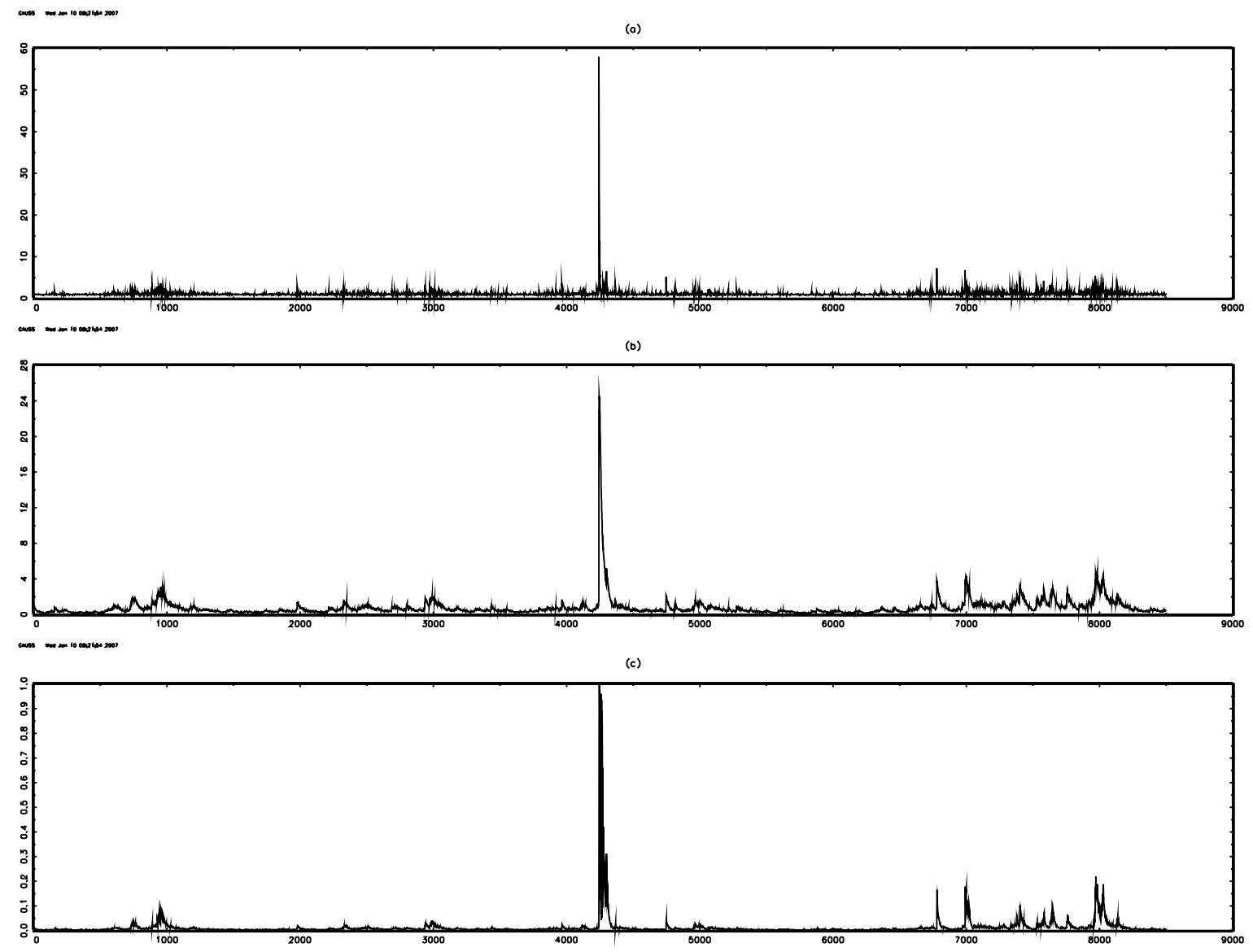

Figure 6: First volatility component $\left(h_{1 t}^{2}, \mathrm{a}\right)$, second volatility component $\left(h_{2 t}^{2}, \mathrm{~b}\right)$, weights series $\left(w_{t}, c\right)$ from the $t$-WGARCH model 

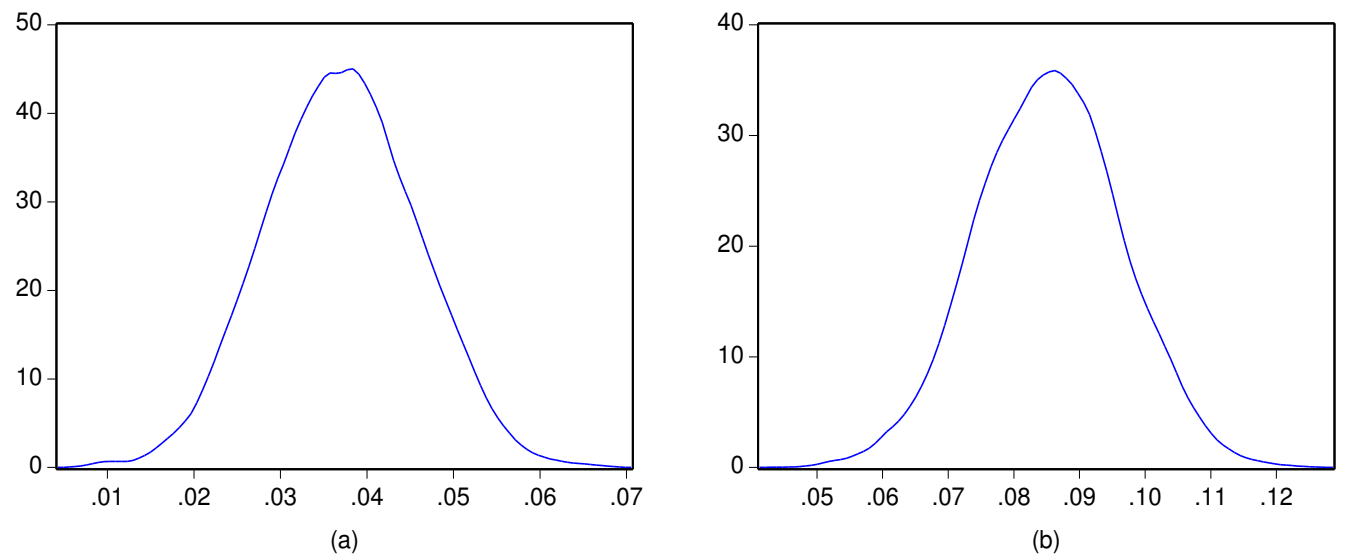

Figure 7: Kernel estimates of the posterior densities of $\phi_{0}$ (a) and $\phi_{1}$ (b) for the normal WGARCH model
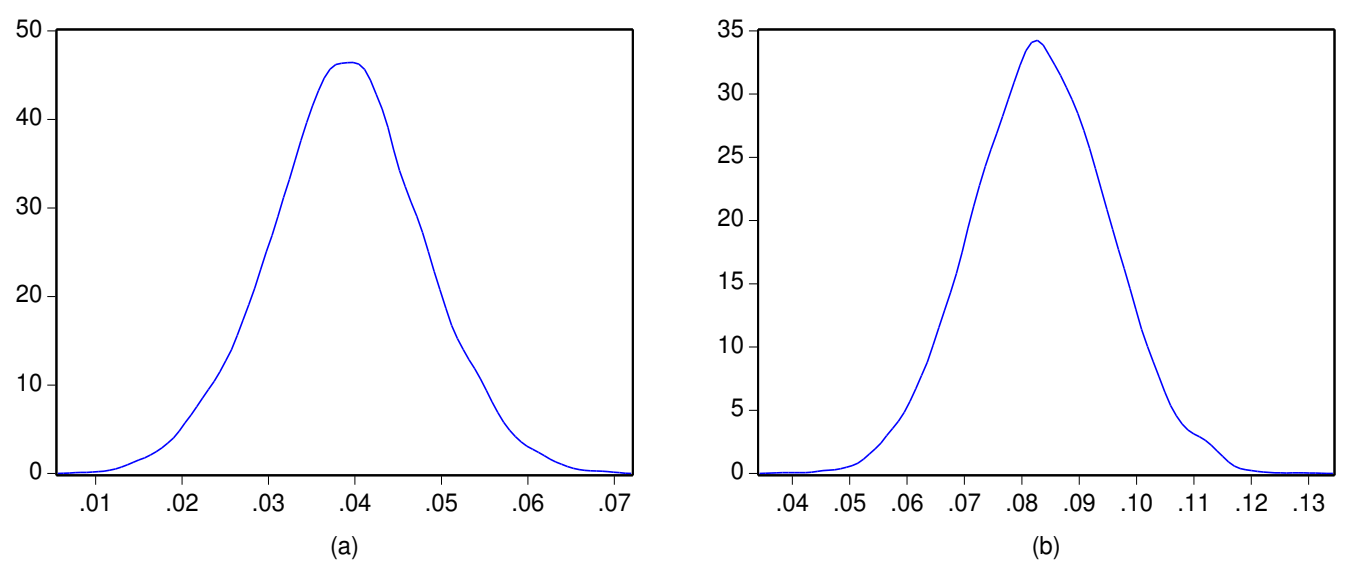

Figure 8: Kernel estimates of the posterior densities of $\phi_{0}$ (a) and $\phi_{1}$ (b) for the $t$ WGARCH model 


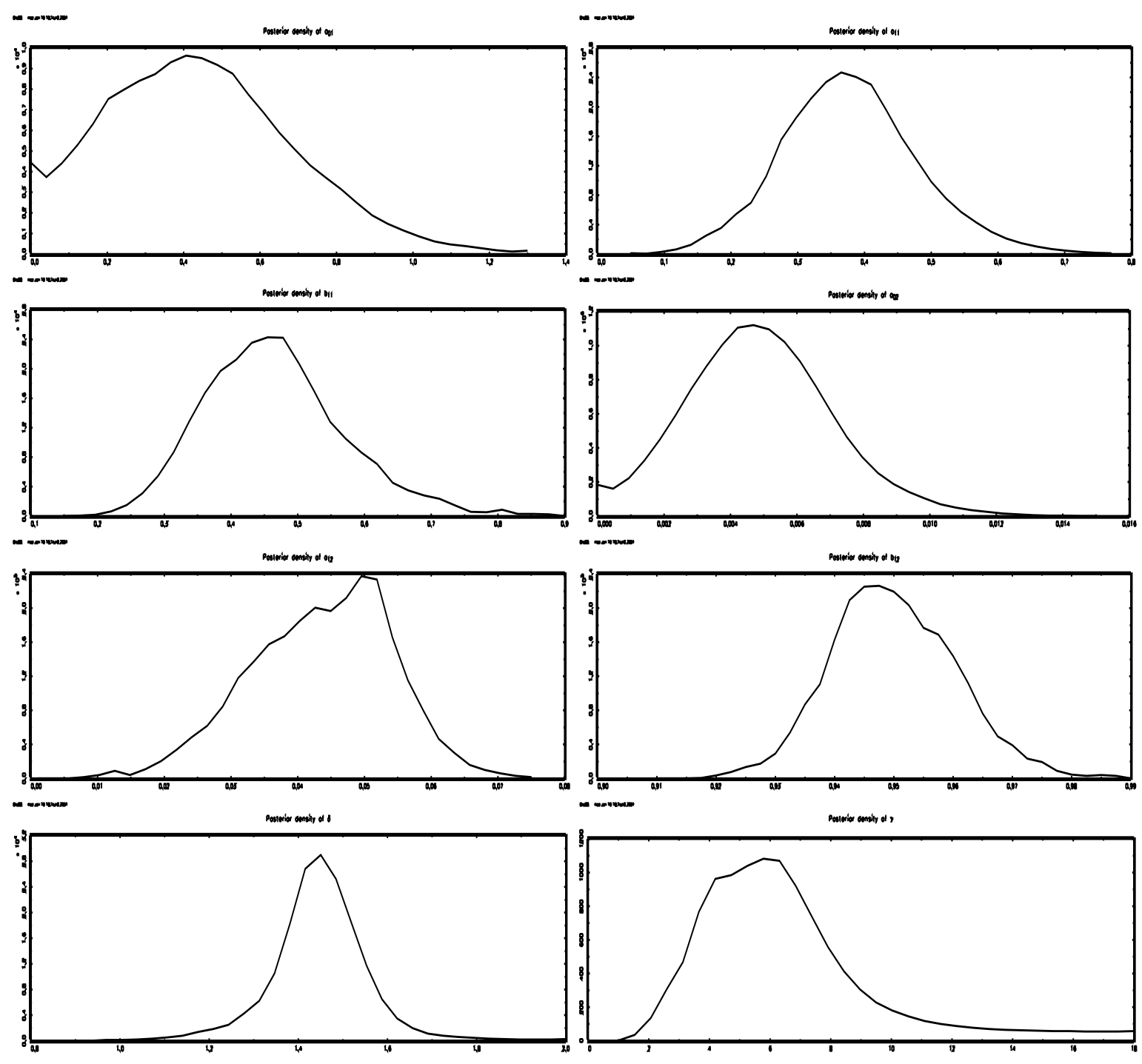

Figure 9: Estimated marginal posteriors of the parameters of the volatility model for the normal WGARCH model. From left to right and from top to bottom: $a_{01}, a_{11}, b_{11}, a_{02}, a_{12}, b_{12}, \delta$, $\gamma$. 


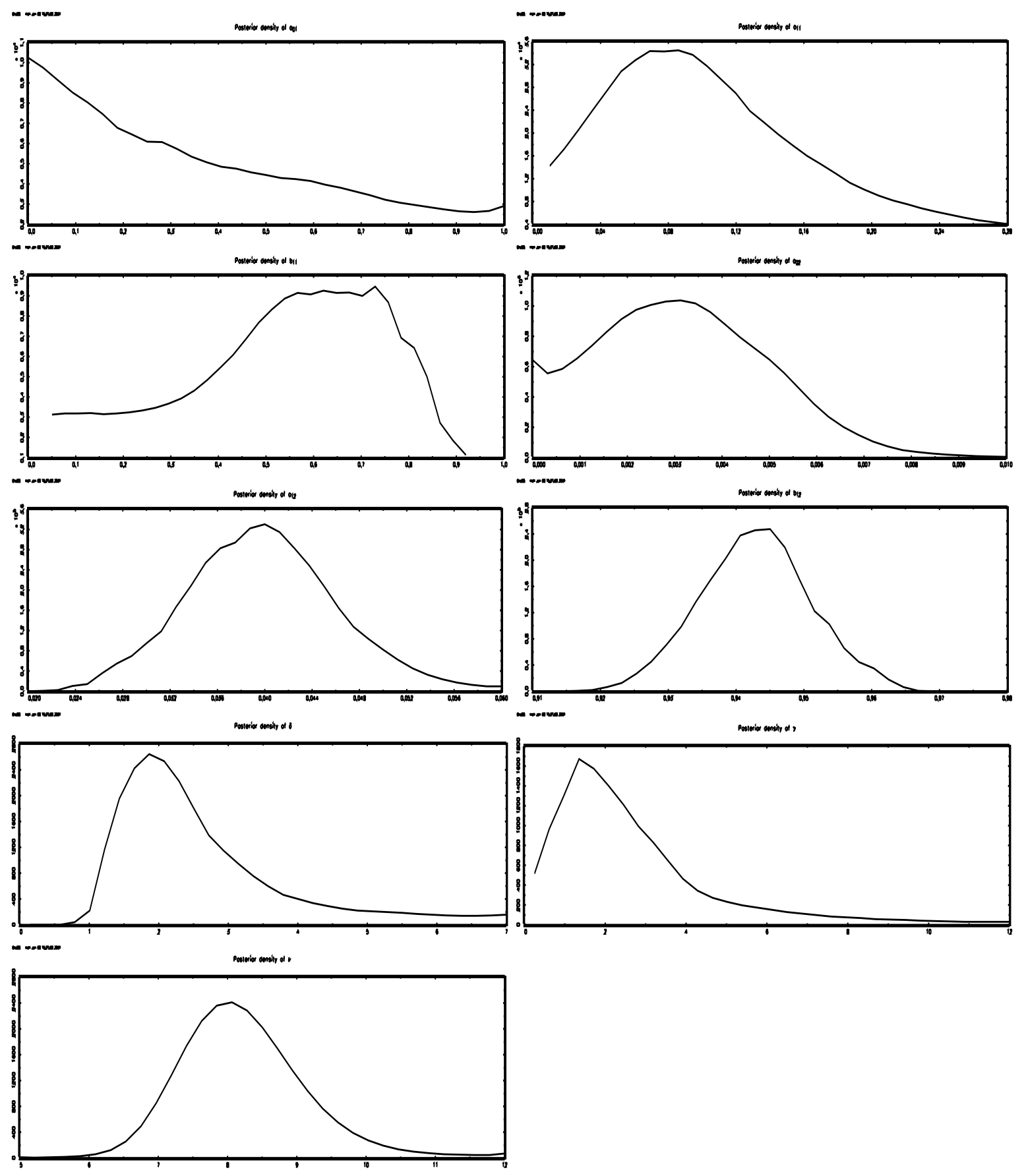

Figure 10: Estimated marginal posteriors of the parameters of the volatility model for the $t$ WGARCH model. From left to right and from top to bottom: $a_{01}, a_{11}, b_{11}, a_{02}, a_{12}, b_{12}, \delta, \gamma, n u$. 
Table 3: Out-of-sample empirical coverages of the normal WGARCH $\left(W G_{n}\right)$, t-WGARCH $\left(W G_{t}\right)$, normal GARCH $\left(G_{n}\right)$ and $t$-GARCH $\left(G_{t}\right)$ models for different confidence levels $(\alpha)$, horizons, long (L) and short (S) positions. Values in brackets are $p$-values of Kupiec's likelihood ratio test statistic for correct unconditional coverage

Long positions

Short positions

\begin{tabular}{|c|c|c|c|c|c|c|c|c|c|}
\hline$\alpha$ & $\mathrm{WG}_{n}$ & $\mathrm{WG}_{t}$ & $\mathrm{G}_{n}$ & $\mathrm{G}_{t}$ & $\mathrm{WG}_{n}$ & $\mathrm{WG}_{t}$ & $\mathrm{G}_{n}$ & $\mathrm{G}_{t}$ & hor. \\
\hline 0.10 & $\begin{array}{l}0.0921 \\
(0.5215)\end{array}$ & $\begin{array}{l}0.1399 \\
(0.0022)\end{array}$ & $\begin{array}{l}0.0921 \\
(0.5215)\end{array}$ & $\begin{array}{l}0.1502 \\
(0.0001)\end{array}$ & $\begin{array}{l}0.0819 \\
(0.1331)\end{array}$ & $\begin{array}{l}0.1212 \\
(0.0972)\end{array}$ & $\begin{array}{l}0.0836 \\
(0.1749)\end{array}$ & $\begin{array}{l}0.1263 \\
(0.0407)\end{array}$ & \multirow[t]{4}{*}{$1 d$} \\
\hline 0.05 & $\begin{array}{l}0.0392 \\
(0.2154)\end{array}$ & $\begin{array}{l}0.0648 \\
(0.1141)\end{array}$ & $\begin{array}{l}0.0444 \\
(0.5240)\end{array}$ & $\begin{array}{l}0.0751 \\
(0.0093)\end{array}$ & $\begin{array}{l}0.0430 \\
(0.4036)\end{array}$ & $\begin{array}{l}0.0631 \\
(0.1601)\end{array}$ & $\begin{array}{l}0.0392 \\
(0.2154)\end{array}$ & $\begin{array}{l}0.0631 \\
(0.1601)\end{array}$ & \\
\hline 0.025 & $\begin{array}{l}0.0205 \\
(0.4694)\end{array}$ & $\begin{array}{l}0.0307 \\
(0.3918)\end{array}$ & $\begin{array}{l}0.0205 \\
(0.4694)\end{array}$ & $\begin{array}{l}0.0410 \\
(0.0233)\end{array}$ & $\begin{array}{l}0.0256 \\
(0.9265)\end{array}$ & $\begin{array}{l}0.0358 \\
(0.1143)\end{array}$ & $\begin{array}{l}0.0256 \\
(0.9265)\end{array}$ & $\begin{array}{l}0.0375 \\
(0.0699)\end{array}$ & \\
\hline 0.01 & $\begin{array}{l}0.0085 \\
(0.7142)\end{array}$ & $\begin{array}{r}0.0153 \\
(0.2269)\end{array}$ & $\begin{array}{r}0.0085 \\
(0.7142)\end{array}$ & $\begin{array}{l}0.0190 \\
(0.0571)\end{array}$ & $\begin{array}{r}0.0085 \\
(0.7142)\end{array}$ & $\begin{array}{r}0.0119 \\
(0.6461)\end{array}$ & $\begin{array}{l}0.0068 \\
(0.4127) \\
\end{array}$ & $\begin{array}{l}0.0154 \\
(0.2269) \\
\end{array}$ & \\
\hline 0.10 & $\begin{array}{l}0.0722 \\
(0.0191)\end{array}$ & $\begin{array}{l}0.1065 \\
(0.6030)\end{array}$ & $\begin{array}{l}0.0773 \\
(0.0585)\end{array}$ & $\begin{array}{l}0.1092 \\
(0.5122)\end{array}$ & $\begin{array}{l}0.0412 \\
(0.0000)\end{array}$ & $\begin{array}{l}0.0687 \\
(0.0080)\end{array}$ & $\begin{array}{l}0.0378 \\
(0.0000)\end{array}$ & $\begin{array}{l}0.0722 \\
(0.0191)\end{array}$ & \multirow[t]{4}{*}{$5 d$} \\
\hline 0.05 & $\begin{array}{l}0.0292 \\
(0.0129)\end{array}$ & $\begin{array}{l}0.0515 \\
(0.8647)\end{array}$ & $\begin{array}{l}0.0309 \\
(0.0235)\end{array}$ & $\begin{array}{l}0.0584 \\
(0.3635)\end{array}$ & $\begin{array}{l}0.0086 \\
(0.0000)\end{array}$ & $\begin{array}{l}0.0240 \\
(0.0015)\end{array}$ & $\begin{array}{l}0.0069 \\
(0.0000)\end{array}$ & $\begin{array}{l}0.0275 \\
(0.0066)\end{array}$ & \\
\hline 0.025 & $\begin{array}{l}0.0120 \\
(0.0260)\end{array}$ & $\begin{array}{l}0.0240 \\
(0.8832)\end{array}$ & $\begin{array}{l}0.0069 \\
(0.0009)\end{array}$ & $\begin{array}{l}0.0292 \\
(0.5262)\end{array}$ & $\begin{array}{l}0.0017 \\
(0.0000)\end{array}$ & $\begin{array}{l}0.0034 \\
(0.0000)\end{array}$ & $\begin{array}{l}0.0017 \\
(0.0000)\end{array}$ & $\begin{array}{l}0.0069 \\
(0.0009)\end{array}$ & \\
\hline 0.01 & $\begin{array}{r}0.0016 \\
(0.0131)\end{array}$ & $\begin{array}{r}0.0069 \\
(0.4217)\end{array}$ & $\begin{array}{r}0.0017 \\
(0.0131)\end{array}$ & $\begin{array}{r}0.0069 \\
(0.4217)\end{array}$ & $\begin{array}{c}0.0000 \\
(.)\end{array}$ & $\begin{array}{c}0.017 \\
(0.0131)\end{array}$ & $\begin{array}{c}0.0000 \\
(.)\end{array}$ & $\begin{array}{l}0.0017 \\
(0.0131) \\
\end{array}$ & \\
\hline 0.10 & $\begin{array}{l}0.0503 \\
(0.0000)\end{array}$ & $\begin{array}{l}0.0901 \\
(0.4219)\end{array}$ & $\begin{array}{l}0.0573 \\
(0.0000)\end{array}$ & $\begin{array}{l}0.1023 \\
(0.8573)\end{array}$ & $\begin{array}{l}0.0156 \\
(0.0000)\end{array}$ & $\begin{array}{l}0.0485 \\
(0.0000)\end{array}$ & $\begin{array}{l}0.0156 \\
(0.0000)\end{array}$ & $\begin{array}{l}0.0537 \\
(0.0001)\end{array}$ & \multirow[t]{4}{*}{$10 d$} \\
\hline 0.05 & $\begin{array}{l}0.0191 \\
(0.0001)\end{array}$ & $\begin{array}{l}0.0364 \\
(0.1158)\end{array}$ & $\begin{array}{l}0.0191 \\
(0.0001)\end{array}$ & $\begin{array}{l}0.0433 \\
(0.4521)\end{array}$ & $\begin{array}{l}0.0069 \\
(0.0000)\end{array}$ & $\begin{array}{l}0.0121 \\
(0.0000)\end{array}$ & $\begin{array}{l}0.0156 \\
(0.0000)\end{array}$ & $\begin{array}{l}0.0121 \\
(0.0000)\end{array}$ & \\
\hline 0.025 & $\begin{array}{l}0.0104 \\
(0.0111)\end{array}$ & $\begin{array}{l}0.0173 \\
(0.2121)\end{array}$ & $\begin{array}{l}0.0104 \\
(0.0111)\end{array}$ & $\begin{array}{l}0.0208 \\
(0.5056)\end{array}$ & $\begin{array}{l}0.0035 \\
(0.0000)\end{array}$ & $\begin{array}{l}0.0052 \\
(0.0002)\end{array}$ & $\begin{array}{l}0.0156 \\
(0.0000)\end{array}$ & $\begin{array}{c}0.0069 \\
(0.0010)\end{array}$ & \\
\hline 0.01 & $\begin{array}{l}0.0052 \\
(0.2018) \\
\end{array}$ & $\begin{array}{l}0.0087 \\
(0.7416)\end{array}$ & $\begin{array}{l}0.0052 \\
(0.2018)\end{array}$ & $\begin{array}{l}0.0104 \\
(0.9238)\end{array}$ & $\begin{array}{l}0.0017 \\
(0.0137)\end{array}$ & & $\begin{array}{c}0.0000 \\
(.)\end{array}$ & $\begin{array}{l}0.0035 \\
(0.0682) \\
\end{array}$ & \\
\hline 0.10 & $\begin{array}{l}0.0524 \\
(0.0000)\end{array}$ & $\begin{array}{l}0.0891 \\
(0.3796)\end{array}$ & $\begin{array}{l}0.0507 \\
(0.0000)\end{array}$ & $\begin{array}{l}0.0909 \\
(0.4624)\end{array}$ & $\begin{array}{l}0.0210 \\
(0.0000)\end{array}$ & $\begin{array}{l}0.0402 \\
(0.0000)\end{array}$ & $\begin{array}{l}0.0140 \\
(0.0000)\end{array}$ & $\begin{array}{l}0.0332 \\
(0.0000)\end{array}$ & \multirow[t]{4}{*}{$15 d$} \\
\hline 0.05 & $\begin{array}{c}0.01075 \\
(0.0000)\end{array}$ & $\begin{array}{c}0.0402 \\
(0.2667\end{array}$ & $\begin{array}{l}0.0122 \\
(0.0000)\end{array}$ & $\begin{array}{l}0.0437 \\
(0.4807)\end{array}$ & $\begin{array}{l}0.0052 \\
(0.0000)\end{array}$ & $\begin{array}{l}0.0140 \\
(0.0000)\end{array}$ & $\begin{array}{l}0.0052 \\
(0.0000)\end{array}$ & $\begin{array}{l}0.0140 \\
(0.0000)\end{array}$ & \\
\hline 0.025 & $\begin{array}{l}0.0035 \\
(0.0000)\end{array}$ & $\begin{array}{l}0.0140 \\
(0.0661)\end{array}$ & $\begin{array}{l}0.0017 \\
(0.0000)\end{array}$ & $\begin{array}{l}0.0157 \\
(0.1281)\end{array}$ & $\begin{array}{l}0.0035 \\
(0.0000)\end{array}$ & $\begin{array}{l}0.0052 \\
(0.0002)\end{array}$ & $\begin{array}{l}0.0035 \\
(0.0000)\end{array}$ & $\begin{array}{l}0.0052 \\
(0.0002)\end{array}$ & \\
\hline 0.01 & $\begin{array}{c}0.0000 \\
(.)\end{array}$ & $\begin{array}{c}0.0000 \\
(.)\end{array}$ & $\begin{array}{c}0.0000 \\
(.)\end{array}$ & & $\begin{array}{c}0.0000 \\
(.)\end{array}$ & & $\begin{array}{c}0.0000 \\
(.)\end{array}$ & $\begin{array}{l}0.0035 \\
(0.0709) \\
\end{array}$ & \\
\hline 0.10 & $\begin{array}{l}0.0564 \\
(0.0002)\end{array}$ & $\begin{array}{l}0.0917 \\
(0.5052)\end{array}$ & $\begin{array}{l}0.0529 \\
(0.0002)\end{array}$ & $\begin{array}{l}0.0970 \\
(0.8111)\end{array}$ & $\begin{array}{l}0.0176 \\
(0.0000)\end{array}$ & $\begin{array}{l}0.0353 \\
(0.0000)\end{array}$ & $\begin{array}{l}0.0176 \\
(0.0000)\end{array}$ & $\begin{array}{l}0.0335 \\
(0.0000)\end{array}$ & \multirow[t]{4}{*}{$20 d$} \\
\hline 0.05 & $\begin{array}{l}0.0106 \\
(0.0000)\end{array}$ & $\begin{array}{l}0.0423 \\
(0.3898)\end{array}$ & & & $\begin{array}{l}0.0053 \\
(0.0000)\end{array}$ & $\begin{array}{l}0.0159 \\
(0.0000)\end{array}$ & & $\begin{array}{l}0.0159 \\
(0.0000)\end{array}$ & \\
\hline 0.025 & $\begin{array}{l}0.0035 \\
(0.0000)\end{array}$ & $\begin{array}{l}0.0106 \\
(0.0131)\end{array}$ & $\begin{array}{c}0.0000 \\
(.)\end{array}$ & $\begin{array}{l}0.0106 \\
(0.0131)\end{array}$ & $\begin{array}{c}0.0000 \\
(.)\end{array}$ & $\begin{array}{l}0.0053 \\
(0.0003)\end{array}$ & $\begin{array}{c}0.0000 \\
(.)\end{array}$ & $\begin{array}{l}0.0088 \\
(0.0044)\end{array}$ & \\
\hline 0.01 & 0.0000 & $\begin{array}{c}0.0018 \\
(0.0151)\end{array}$ & $\begin{array}{c}0.0000 \\
(.)\end{array}$ & $\begin{array}{l}0.0035 \\
(0.0738)\end{array}$ & $\begin{array}{c}0.0000 \\
(.)\end{array}$ & $\begin{array}{c}0.0000 \\
(.)\end{array}$ & $\underset{(.)}{0.0000}$ & 0.0000 & \\
\hline
\end{tabular}


Table 4: Out-of-sample predictive densities estimated by WGARCH $\left(\mathrm{WG}_{n}\right), t$ WGARCH $\left(\mathrm{WG}_{t}\right)$, normal GARCH $\left(\mathrm{G}_{n}\right)$ and $t$-GARCH $\left(\mathrm{G}_{t}\right)$ models. Values in brackets are $p$-values associated with the censored likelihood ratio test statistic proposed by Berkowitz (2001).

Long positions

Short positions

\begin{tabular}{|c|c|c|c|c|c|c|c|c|c|}
\hline$\alpha$ & $\mathrm{WG}_{n}$ & $\mathrm{WG}_{t}$ & $\mathrm{G}_{n}$ & $\mathrm{G}_{t}$ & $\mathrm{WG}_{n}$ & $\mathrm{WG}_{t}$ & $\mathrm{G}_{n}$ & $\mathrm{G}_{t}$ & hor. \\
\hline 0.10 & $\begin{array}{l}0.3646 \\
(0.8333)\end{array}$ & $\begin{array}{c}4.343 \\
(0.1140)\end{array}$ & $\begin{array}{l}0.1882 \\
(0.9102)\end{array}$ & $\begin{array}{c}6.315 \\
(0.0425)\end{array}$ & $\begin{array}{l}0.9727 \\
(0.6149)\end{array}$ & $\begin{array}{c}1.274 \\
(0.5288)\end{array}$ & $\begin{array}{l}0.8417 \\
(0.6565)\end{array}$ & $\begin{array}{c}1.947 \\
(0.3778)\end{array}$ & \multirow[t]{4}{*}{$1 d$} \\
\hline 0.05 & $\begin{array}{l}0.6722 \\
(0.7145)\end{array}$ & $\begin{array}{c}1.218 \\
(0.5439)\end{array}$ & $\begin{array}{l}0.2097 \\
(0.9004)\end{array}$ & $\begin{array}{c}3.006 \\
(0.2224)\end{array}$ & $\begin{array}{l}0.3235 \\
(0.8506)\end{array}$ & $\begin{array}{c}1.004 \\
(0.6053)\end{array}$ & $\begin{array}{l}0.8974 \\
(0.6384)\end{array}$ & $\begin{array}{l}0.9356 \\
(0.6264)\end{array}$ & \\
\hline 0.025 & $\begin{array}{l}0.2217 \\
(0.8951)\end{array}$ & $\begin{array}{l}0.4455 \\
(0.8003)\end{array}$ & $\begin{array}{l}0.3813 \\
(0.8264)\end{array}$ & $\begin{array}{c}2.451 \\
(0.2937)\end{array}$ & $\begin{array}{l}0.5845 \\
(0.7466)\end{array}$ & $\begin{array}{c}1.708 \\
(0.4257)\end{array}$ & $\begin{array}{l}0.3193 \\
(0.8524)\end{array}$ & $\begin{array}{c}1.679 \\
(0.4319)\end{array}$ & \\
\hline 0.01 & $\begin{array}{r}0.1323 \\
(0.9360) \\
\end{array}$ & $\begin{array}{c}2.094 \\
(0.3511) \\
\end{array}$ & $\begin{array}{r}0.1286 \\
(0.9377) \\
\end{array}$ & $\begin{array}{c}2.278 \\
(0.3201) \\
\end{array}$ & $\begin{array}{l}0.3611 \\
(0.8348) \\
\end{array}$ & $\begin{array}{l}0.8112 \\
(0.6666) \\
\end{array}$ & $\begin{array}{l}0.3204 \\
(0.8520) \\
\end{array}$ & $\begin{array}{c}1.572 \\
(0.4557) \\
\end{array}$ & \\
\hline 0.10 & $\begin{array}{c}3.496 \\
(0.1741)\end{array}$ & $\begin{array}{l}0.3044 \\
(0.8588)\end{array}$ & $\begin{array}{c}4.064 \\
(0.1311)\end{array}$ & $\begin{array}{l}0.2523 \\
(0.8815)\end{array}$ & $\begin{array}{l}17.790 \\
(0.0001)\end{array}$ & $\begin{array}{c}7.383 \\
(0.0249)\end{array}$ & $\begin{array}{l}18.900 \\
(0.0001)\end{array}$ & $\begin{array}{c}5.932 \\
(0.0675)\end{array}$ & \multirow[t]{3}{*}{$5 d$} \\
\hline 0.05 & $\begin{array}{c}3.198 \\
(0.2021)\end{array}$ & $\begin{array}{l}0.2321 \\
(0.8904)\end{array}$ & $\begin{array}{c}4.454 \\
(0.1079)\end{array}$ & $\begin{array}{l}0.7378 \\
(0.6915)\end{array}$ & $\begin{array}{l}16.140 \\
(0.0003)\end{array}$ & $\begin{array}{c}7.289 \\
(0.0261)\end{array}$ & $\begin{array}{l}16.450 \\
(0.0003)\end{array}$ & $\begin{array}{c}5.150 \\
(0.0761)\end{array}$ & \\
\hline 0.025 & $\begin{array}{c}2.761 \\
(0.2515) \\
\end{array}$ & $\begin{array}{r}0.3225 \\
(0.8511) \\
\end{array}$ & $\begin{array}{c}4.971 \\
(0.0833) \\
\end{array}$ & $\begin{array}{c}1.339 \\
(0.5121) \\
\end{array}$ & $\begin{array}{c}9.923 \\
(0.0070) \\
\end{array}$ & $\begin{array}{c}7.716 \\
(0.0211) \\
\end{array}$ & & $\begin{array}{c}5.286 \\
(0.0714) \\
\end{array}$ & \\
\hline 0.10 & $\begin{array}{c}8.483 \\
(0.0144)\end{array}$ & $\begin{array}{l}0.5457 \\
(0.7612)\end{array}$ & $\begin{array}{c}7.993 \\
(0.0184)\end{array}$ & $\begin{array}{l}0.3576 \\
(0.8363)\end{array}$ & $\begin{array}{l}29.690 \\
(0.0000)\end{array}$ & $\begin{array}{l}11.490 \\
(0.0032)\end{array}$ & $\begin{array}{l}29.880 \\
(0.0000)\end{array}$ & $\begin{array}{c}9.291 \\
(0.0096)\end{array}$ & \multirow[t]{3}{*}{$10 d$} \\
\hline 0.05 & $\begin{array}{c}6.484 \\
(0.0391)\end{array}$ & $\begin{array}{c}1.079 \\
(0.5830)\end{array}$ & $\begin{array}{c}6.557 \\
(0.0377)\end{array}$ & $\begin{array}{l}0.2357 \\
(0.8888)\end{array}$ & $\begin{array}{l}15.190 \\
(0.0005)\end{array}$ & $\begin{array}{l}10.730 \\
(0.0047)\end{array}$ & $\begin{array}{l}15.320 \\
(0.0005)\end{array}$ & $\begin{array}{l}10.890 \\
(0.0043)\end{array}$ & \\
\hline 0.025 & $\begin{array}{c}2.758 \\
(0.2518) \\
\end{array}$ & $\begin{array}{l}0.7127 \\
(0.7002) \\
\end{array}$ & $\begin{array}{c}2.869 \\
(0.2383) \\
\end{array}$ & $\begin{array}{r}0.0185 \\
(0.9115) \\
\end{array}$ & $\begin{array}{c}7.455 \\
(0.0240) \\
\end{array}$ & $\begin{array}{c}5.959 \\
(0.0508) \\
\end{array}$ & $\begin{array}{c}7.642 \\
(0.0022) \\
\end{array}$ & $\begin{array}{c}4.739 \\
(0.0935) \\
\end{array}$ & \\
\hline 0.10 & $\begin{array}{l}11.530 \\
(0.0031)\end{array}$ & $\begin{array}{c}2.199 \\
(0.3330)\end{array}$ & $\begin{array}{l}13.700 \\
(0.0011)\end{array}$ & $\begin{array}{c}1.835 \\
(0.3996)\end{array}$ & $\begin{array}{l}26.720 \\
(0.0000)\end{array}$ & $\begin{array}{l}14.530 \\
(0.0007)\end{array}$ & $\begin{array}{l}31.060 \\
(0.0000)\end{array}$ & $\begin{array}{l}16.240 \\
(0.0003)\end{array}$ & \multirow[t]{3}{*}{$15 d$} \\
\hline 0.05 & $\begin{array}{l}10.070 \\
(0.0065)\end{array}$ & $\begin{array}{c}2.994 \\
(0.2238)\end{array}$ & $\begin{array}{l}13.140 \\
(0.0014)\end{array}$ & $\begin{array}{c}2.865 \\
(0.2387)\end{array}$ & $\begin{array}{l}16.820 \\
(0.0002)\end{array}$ & $\begin{array}{c}9.488 \\
(0.0087)\end{array}$ & $\begin{array}{l}16.830 \\
(0.0002)\end{array}$ & $\begin{array}{c}9.388 \\
(0.0091)\end{array}$ & \\
\hline 0.025 & $\begin{array}{c}8.645 \\
(0.0133) \\
\end{array}$ & $\begin{array}{c}3.279 \\
(0.1941) \\
\end{array}$ & $\begin{array}{l}10.330 \\
(0.0057) \\
\end{array}$ & $\begin{array}{c}3.207 \\
(0.2012) \\
\end{array}$ & $\begin{array}{c}7.453 \\
(0.0241) \\
\end{array}$ & $\begin{array}{c}5.833 \\
(0.0541) \\
\end{array}$ & $\begin{array}{c}7.467 \\
(0.0239) \\
\end{array}$ & $\begin{array}{c}6.024 \\
(0.0492) \\
\end{array}$ & \\
\hline 0.10 & $\begin{array}{l}12.830 \\
(0.0016)\end{array}$ & $\begin{array}{c}2.373 \\
(0.3052)\end{array}$ & $\begin{array}{l}16.450 \\
(0.0003)\end{array}$ & $\begin{array}{c}2.232 \\
(0.3276)\end{array}$ & $\begin{array}{l}28.170 \\
(0.0000)\end{array}$ & $\begin{array}{l}16.630 \\
(0.0003)\end{array}$ & $\begin{array}{l}30.220 \\
(0.0000)\end{array}$ & $\begin{array}{l}16.010 \\
(0.0003)\end{array}$ & \multirow[t]{3}{*}{$20 d$} \\
\hline 0.05 & $\begin{array}{l}12.690 \\
(0.0018)\end{array}$ & $\begin{array}{c}4.344 \\
(0.1140)\end{array}$ & $\begin{array}{l}14.050 \\
(0.0009)\end{array}$ & $\begin{array}{c}4.166 \\
(0.1245)\end{array}$ & $\begin{array}{l}18.630 \\
(0.0001)\end{array}$ & $\begin{array}{c}9.185 \\
(0.0103)\end{array}$ & $\begin{array}{r}22.210 \\
(0.0000)\end{array}$ & $\begin{array}{c}8.376 \\
(0.0152)\end{array}$ & \\
\hline 0.025 & $\begin{array}{c}9.234 \\
(0.0099)\end{array}$ & $\begin{array}{c}3.683 \\
(0.1586)\end{array}$ & $\begin{array}{l}12.470 \\
(0.0020)\end{array}$ & $\begin{array}{c}3.395 \\
(0.1831)\end{array}$ & $\begin{array}{l}12.470 \\
(0.0020)\end{array}$ & $\begin{array}{c}7.408 \\
(0.0246)\end{array}$ & $\begin{array}{l}12.470 \\
(0.0002)\end{array}$ & $\begin{array}{c}6.409 \\
(0.0406)\end{array}$ & \\
\hline
\end{tabular}


Département des Sciences Économiques de l'Université catholique de Louvain

Institut de Recherches Économiques et Sociales

Place Montesquieu, 3

1348 Louvain-la-Neuve, Belgique 